\title{
$\beta$-Hydroxybutyrate Modulates N-Type Calcium Channels in Rat Sympathetic Neurons by Acting as an Agonist for the G-Protein-Coupled Receptor FFA3
}

\author{
Yu-Jin Won, Van B. Lu, Henry L. Puhl III, and Stephen R. Ikeda \\ Section on Transmitter Signaling, Laboratory of Molecular Physiology, National Institute on Alcohol Abuse and Alcoholism, National Institutes of Health, \\ Bethesda, Maryland 20892-9411
}

Free fatty acids receptor 3 (FFA3, GPR41) and 2 (FFA2, GPR43), for which the short-chain fatty acids (SCFAs) acetate and propionate are agonist, have emerged as important G-protein-coupled receptors influenced by diet and gut flora composition. A recent study (Kimura et al., 2011) demonstrated functional expression of FFA3 in the rodent sympathetic nervous system (SNS) providing a potential link between nutritional status and autonomic function. However, little is known of the source of endogenous ligands, signaling pathways, or effectors in sympathetic neurons. In this study, we found that FFA3 and FFA2 are unevenly expressed in the rat SNS with higher transcript levels in prevertebral (e.g., celiac-superior mesenteric and major pelvic) versus paravertebral (e.g., superior cervical and stellate) ganglia. FFA3, whether heterologously or natively expressed, coupled via PTX-sensitive G-proteins to produce voltage-dependent inhibition of $\mathrm{N}$-type $\mathrm{Ca}^{2+}$ channels $\left(\mathrm{Ca}_{\mathrm{v}} 2.2\right)$ in sympathetic neurons. In addition to acetate and propionate, we show that $\beta$-hydroxybutyrate (BHB), a metabolite produced during ketogenic conditions, is also an FFA3 agonist. This contrasts with previous interpretations of BHB as an antagonist at FFA3. Together, these results indicate that endogenous BHB levels, especially when elevated under certain conditions, such as starvation, diabetic ketoacidosis, and ketogenic diets, play a potentially important role in regulating the activity of the SNS through FFA3.

\section{Introduction}

Free fatty acid receptor 3 (FFA3) and 2 (FFA2), originally termed GPR41 and GPR43, respectively, are paralogs in a G-proteincoupled receptor (GPCR) family tandemly encoded at a single chromosomal locus. Short-chain fatty acids (SCFAs), most notably, acetate $(\mathrm{C} 2)$, propionate $(\mathrm{C} 3)$, and butyrate $(\mathrm{C} 4)$, are potential endogenous agonists for FFA2 and FFA3 (Brown et al., 2003; Le Poul et al., 2003; Nilsson et al., 2003). Anerobic bacterial fermentation of undigested carbohydrate in the lower gut is the major source for SCFAs (Sellin, 1999; Topping and Clifton, 2001). FFA3 and FFA2 are expressed in the intestine where SCFAs are produced (Karaki et al., 2008; Samuel et al., 2008; Tazoe et al., 2009) as well as at other sites involved with metabolism, including pancreatic islets, blood cells (monocytes and neutrophils), and white adipose tissue (Le Poul et al., 2003; Nilsson et al., 2003; Xiong et al., 2004; Brown et al., 2005; Kebede et al., 2009).

\footnotetext{
Received July 22, 2013; revised 0ct. 23, 2013; accepted 0ct. 29, 2013.

Author contributions:Y.-J.W., H.L.P., and S.R.I. designed research;Y.-J.W., V.B.L., and H.L.P. performed research; Y.-J.W. and H.L.P. contributed unpublished reagents/analytic tools; Y.-J.W., V.B.L., and S.R.I. analyzed data; Y.-J.W. and S.R.I. wrote the paper.

This work was supported by the intramural program at the National Institutes of Health, National Institute on Alcohol Abuse and Alcoholism.

The authors declare no competing financial interests.

Correspondence should be addressed to Dr. Stephen R. Ikeda, Laboratory of Molecular Physiology, National Institutes of Health/National Institute on Alcohol Abuse and Alcoholism, 5625 Fishers Lane, Room TS-11, Rockville, MD 20852. E-mail: sikeda@mail.nih.gov.

DOI:10.1523/JNEUROSCI.3102-13.2013

Copyright $\odot 2013$ the authors $\quad 0270-6474 / 13 / 3319314-12 \$ 15.00 / 0$
}

Recently, SCFAs and a ketone body, $\beta$-hydroxybutyrate (BHB), were reported to regulate the sympathetic nervous system (SNS) directly through FFA3 expressed in sympathetic superior cervical ganglionic (SCG) neurons (Kimura et al., 2011). In this study, SCFAs promoted sympathetic outflow by serving as agonists for FFA3, whereas $\mathrm{BHB}$, a metabolite produced during ketogenic conditions, antagonized FFA3, thereby suppressing the SNS. Under conditions, such as fasting, diabetes, and ethanol consumption, endogenous ligands for FFA3 attain plasma concentrations (low millimolar) sufficient to activate the receptor, thereby potentially influencing body energy expenditure and metabolic homeostasis. However, thus far, physiological signaling pathways for FFA3 in sympathetic neurons are unknown. Moreover, the source of the endogenous ligands for activating FFA3 in sympathetic ganglia remains unclear.

The majority of FFA3 studies have used biochemical assays in cell lines heterologously expressing the receptor. To better understand the details of native FFA3 signaling in tissue, we used dissociated rat sympathetic neurons as a model system for electrophysiological studies. In this well-explored system, natively and heterologously expressed GPCRs efficiently couple to endogenous $\mathrm{G}$-proteins to modulate natively expressed N-type voltagegated $\mathrm{Ca}^{2+}$ channels after external application of cognate agonists (Ikeda and Schofield, 1989; Zhu and Ikeda, 1993a, b; Ikeda, 1996). Using whole-cell patch-clamp, we examined the pharmacology and signaling pathways of both native and heterologous FFA3 expressed in sympathetic neurons. We found that native FFA3 responses were asymmetric within the SNS with an 
increasing cranial to caudal gradient. FFA3 transcript levels, as determined with qRT-PCR and in situ hybridization, correlated well with the magnitude of physiological responses. Finally, in contrast to previous findings, we identify BHB as an agonist rather than an antagonist at both heterologously and natively expressed FFA3. We conclude that BHB is likely the physiologically relevant endogenous ligand for FFA3 in sympathetic neurons during epochs of increased plasma BHB levels that occur because of starvation, diabetes, or ketogenic diets.

\section{Materials and Methods}

Cloning. The open reading frames for FFAs and GPR109A (accession no. for mFFA3: NM_001033316, mFFA2: BC019570, rFFA3: NM_001108912, rFFA2: NM_001005877, rGPR109A: NM_181476) were amplified by PCR from genomic DNA (gDNA) (mouse, Promega; rat, Clontech) with Phusion polymerase (New England Biolabs). PCR primers incorporated $5^{\prime}$ XhoI and $3^{\prime}$ SacII/TGA/NotI restriction enzyme sites, and the product was cloned into the XhoI/NotI sites of the mammalian expression vector pCI (Promega). The pCI clones were used for the construction of C-terminal fluorescently tagged proteins by restriction digestion of the GPCR inserts with XhoI (5') and SacII (3') followed by cloning these fragments into the same sites in the vector "enhanced" green fluorescent protein (EGFP)-N1 (Clontech). Throughout the manuscript, we use the International Union of Basic and Clinical Pharmacology nomenclature FFA3 and FFA2 for the gene name, transcript, and protein. It should be noted that FFAR3 and FFAR2 (HUGO Gene Nomenclature Committee, UniProt, and UniGene databases) are also in current usage. We refer to GPR41 and GPR43, the original orphan GPCR nomenclature, only within a historic context.

Preparation of ganglia neurons. All of the animal studies were conducted according to the National Institutes of Health's Guidelines for Animal Care and Use. Single neurons of ganglia from adult male Wister rats $(200-250 \mathrm{~g})$ were enzymatically dissociated as described previously (Ikeda and Jeong, 2004; Ikeda, 2004). Animals were anesthetized by $\mathrm{CO}_{2}$ inhalation and subsequently decapitated before dissection. The ganglia were dissected out, desheathed, cut into small pieces, and incubated in the modified EBSS containing collagenase CLS4: $2 \mathrm{mg} / \mathrm{ml}$ for SCG, stellate ganglia (SG), and major pelvic ganglia (MPG), $1 \mathrm{mg} / \mathrm{ml}$ for celiacsuperior mesenteric ganglia complex (CSMG) and nodose (Worthington Biochemical), trypsin TRL $(0.7 \mathrm{mg} / \mathrm{ml}$ for SCG, SG, and MPG, 0.35 $\mathrm{mg} / \mathrm{ml}$ for CSMG and nodose) (Worthington Biochemical), and 0.05 $\mathrm{mg} / \mathrm{ml}$ DNase I (Sigma-Aldrich) at $37^{\circ} \mathrm{C}$ for $60 \mathrm{~min}$. The EBSS was modified by adding $3.6 \mathrm{~g} / \mathrm{L}$ glucose and $10 \mathrm{~mm}$ HEPES. After incubation, neurons were dissociated by vigorous shaking of the flask. The dissociated cells were washed twice, transferred to MEM containing 10\% FBS and $1 \%$ penicillin-streptomycin (all from Invitrogen), plated on poly-Llysine (Sigma-Aldrich) coated tissue culture dishes, and maintained in a humidified $95 \%$ air $/ 5 \% \mathrm{CO}_{2}$ incubator at $37^{\circ} \mathrm{C}$.

Conventional and RT-PCR. Dissociated sympathetic neurons were washed twice with DEPC-treated PBS, pH 7.4, and completely lysed with RLT lysis buffer (QIAGEN). RNA was extracted by using the RNeasy Mini Kit (QIAGEN). gDNA eliminator mini-spin columns (QIAGEN) were used to avoid gDNA contamination at the final step. Synthesis of the first strand of cDNA was performed using QuantiTect Reverse Transcription Kit (QIAGEN) with $2 \mu \mathrm{g}$ total RNA in a final volume of $40 \mu \mathrm{l}$ at $42^{\circ} \mathrm{C}$ for $60 \mathrm{~min}$. PCR amplification was performed by $2 \times$ GoTaq Hot Start Polymerase Green Master Mix (Promega) for 35 cycles consisting of $94^{\circ} \mathrm{C}$ for $30 \mathrm{~s}, 60^{\circ} \mathrm{C}$ for $30 \mathrm{~s}$, and $72^{\circ} \mathrm{C}$ for 1 min $30 \mathrm{~s}$. The final extension was performed at $72^{\circ} \mathrm{C}$ for $5 \mathrm{~min}$. Forward and reverse primer sequences for conventional RT-PCR were targeted to different exons, allowing discrimination of products amplified from mRNA versus gDNA, except for FFA2 and GPR109A, which do not have introns in the open reading frame. The following primer pairs were used: rFFA3 (425 bp); exon 1 forward (bases 114-133), 5' -CTGGTGCTGTAGGAGCTAGC-3', with exon 2 reverse (bases 517-538), 5'-CCACAGTGGGTAGGCTACGCTC-3'; rFFA2 (993 bp); exon 1 forward (bases 1-23), 5' -CACCCGTGCACATCCT CCTGC-3', with exon 1 reverse (bases 971-993), 5' -GATGGTGACTGTCATGGGGACG-3'; rGPR109A (1083 bp); forward (bases 1-26), 5' -
ATGAGCAAGCAGAACCACTTTCTGGT-3', with reverse (bases 10581083), 5' -TTAACGAGATGTGGAAGCCAGATAAG-3'; tyrosine hydroxylase (accession no. NM_012740, 422 bp); exon 8 forward (bases 860-879), 5'-GACTGGCTTCCAGCTGCGAC-3', with exon 12 reverse (bases 1263-1281), 5'-GGTAGGGCTGCACAGCTGC- ${ }^{\prime}$; $\beta$-actin (accession no. NM_031144, 492 bp); exon 4 forward (bases 598-618), 5'-GCCATCCTGCGTCTGGACCTG-3', with exon 6 reverse (bases 10691089), $5^{\prime}$-GTACTTGCGCTCAGGAGGAGC- $3^{\prime}$. $\beta$-Actin mRNA was amplified as an internal reference and to evaluate gDNA contamination in negative controls where the RT reaction was performed without RTase. The PCR products were analyzed by agarose gel electrophoresis and visualized using SYBR safe DNA gel stain (Invitrogen).

qRT-PCR was performed with ABI StepOnePlus Real-Time System using TaqMan Universal PCR Master Mix (all from Applied Biosystems) in accordance with the manufacturer's instructions. Reaction mixture contained $1 \times$ Master mix, $0.1 \mu \mathrm{g}$ template $\mathrm{CDNA}$, and $1 \times$ each FAMFFA primer pairs (ABI, Assay ID for rFFA3: Rn01457614_g1, rFFA2: Rn02345824_s1, rGPR109A: Rn00710718_s1) and $0.3 \times$ rat $\beta$-actin primer pair (VIC/MGB probe, ABI, part no. $4352340 \mathrm{E}$ ) in a total volume of $20 \mu \mathrm{l}$. The mixture was initially heated at $95^{\circ} \mathrm{C}$ for $15 \mathrm{~min}$ and cycled 50 times with two steps of melting at $95^{\circ} \mathrm{C}$ for $15 \mathrm{~s}$ and annealing/extending at $60^{\circ} \mathrm{C}$ for $1 \mathrm{~min}$. All reactions were performed in triplicate. The specific DNA product was confirmed by analysis of a melting curve generated at the end of PCR. As an internal reference, the $\beta$-actin gene was amplified concurrently (i.e., multiplexed). To analyze the relative gene expression, the comparative $2^{-\Delta \Delta \mathrm{C}_{\mathrm{T}}}$ method was used (Schmittgen and Livak, 2008). Briefly, the $\mathrm{C}_{\mathrm{T}}$ values, defined as the PCR cycle at which the fluorescent signal of the reporter dye crosses a threshold determined by StepOne software, were obtained for GPCRs and $\beta$-actin genes. The $\Delta \mathrm{C}_{\mathrm{T}}$ value for each receptor gene was calculated using the equation: $\Delta \mathrm{C}_{\mathrm{T}}=\mathrm{C}_{\mathrm{T}}$ (receptor, i.e., GPCRs) $-\mathrm{C}_{\mathrm{T}}$ (reference, i.e., $\beta$-actin). The fold change in gene expression of GPCRs between the sample groups was finally obtained from the formula $2^{-\Delta \Delta \mathrm{C}_{\mathrm{T}}}: \Delta \Delta \mathrm{C}_{\mathrm{T}}=\left[\Delta \mathrm{C}_{\mathrm{T}}\right.$ (tissue group) $-\Delta \mathrm{C}_{\mathrm{T}}$ (negative tissue group, i.e., DRG or brain group)].

In situ hybridization. The $425 \mathrm{bp}$ rFFA3 PCR product was cloned into pGEM-T Easy vector (Promega), which allows in vitro transcription from either side of the polylinker region. Plasmids were linearized with the restriction enzyme PstI, followed by the generation of digoxigenin (DIG)-labeled antisense transcript using T7 RNA polymerase. Sense control probe was generated by linearization with SacII, followed by transcription with SP6 polymerase. Labeling of RNA probes with DIG-11-UTP was performed according to the manufacturer's recommendation (Roche). The transcription mixture included $1 \mu \mathrm{g}$ of linearized template plasmid, $1 \times$ transcription buffer, NTP mix (10 mM ATP, GTP, CTP, 6.5 mм UTP, 3.5 mм DIG-11-UTP), 2 U/ $\mu$ l RNase inhibitor, and T7 or Sp6 RNA polymerase $(2 \mathrm{U} / \mu \mathrm{l})$ (all from Roche). Transcription was performed for $2 \mathrm{~h}$ at $37^{\circ} \mathrm{C}$ and subsequently stopped by degrading the plasmid with RNase-free DNase ( $50 \mathrm{U} / \mu \mathrm{l}$, Ambion) for $15 \mathrm{~min}$ at $37^{\circ} \mathrm{C}$. The RNA transcript was purified through precipitation with $1 / 10$ volume of $\mathrm{LiCl}$ and 2.5 volumes of ethanol. After the precipitation, the transcript was centrifuged at $13,000 \mathrm{rpm}$ for $15 \mathrm{~min}$ at $4^{\circ} \mathrm{C}$, washed with $70 \%$ ethanol, and then centrifuged $5 \mathrm{~min}$ at $4^{\circ} \mathrm{C}$. The pellet was suspended in RNase-free water and quantified using a 2100 Bioanalyzer (Agilent).

Dissected ganglia were rapidly rinsed in RNase-free PBS and fixed for $3 \mathrm{~h}$ in $4 \%$ PFA at $4^{\circ} \mathrm{C}$. Fixed ganglia were then cryoprotected by incubation in DEPC-treated $30 \%$ sucrose at $4^{\circ} \mathrm{C}$ until submerged. The ganglia were frozen in Tissue-Tek OCT Compound (Sakura Finetek), sectioned at $15 \mu \mathrm{m}$ using a cryostat (CM3050; Leica), and mounted on superFrost Plus slides (VWR International). After fixation in 4\% PFA, the sections were pretreated with $0.2 \mathrm{M} \mathrm{HCl}$ for $10 \mathrm{~min}$, followed by digestion with 10 $\mu \mathrm{g} / \mathrm{ml}$ proteinase $\mathrm{K}$ for $20 \mathrm{~min}$. The sections were washed in PBS $(3 \times 5$ min each) and then prehybridized for $4-5 \mathrm{~h}$ at $60^{\circ} \mathrm{C}$ in hybridization buffer ( $50 \%$ formamide, $5 \times$ SSC, $1 \%$ SDS, $5 \mu \mathrm{g} / \mathrm{ml} \mathrm{tRNA}$, and $5 \mu \mathrm{g} / \mathrm{ml}$ heparin, $5 \times$ Denhardt's solution; all from Invitrogen). The probes were denatured in hybridization buffer $(10 \mathrm{ng} / \mu \mathrm{l})$ for $10 \mathrm{~min}$ at $80^{\circ} \mathrm{C}$, cooled on ice, and then spread over the sections with Parafilm. The hybridization reaction was performed at $60^{\circ} \mathrm{C}$ overnight in a humidified chamber. After incubation, the sections were washed $(3 \times 30 \mathrm{~min}$ each $)$ in wash buffer $(50 \%$ formamide, $2 \times$ SSC, $0.1 \%$ Tween 20$)$ at $60^{\circ} \mathrm{C}$, followed by 
wash $(3 \times 30 \mathrm{~min}$ each) in a second wash buffer ( $50 \%$ formamide, $0.2 \%$ SSC, $0.1 \%$ Tween 20$)$ at room temperature, and finally washed $(2 \times 5$ min each) in Tris-buffered saline with $0.1 \%$ Tween 20 (TBST). The sections were incubated in $1 \%$ blocking solution (Roche) for $2 \mathrm{~h}$ at room temperature followed by overnight incubation at $4^{\circ} \mathrm{C}$ with alkaline phosphatase-coupled anti-DIG antibody (1:1000; Roche). Excess antibody was removed by washing $(5 \times 10 \mathrm{~min}$ each $)$ with TBST. The color development was performed with NBT/BCIP solution substrate (Roche) at room temperature for $4 \mathrm{~h}$. To inactivate the color reaction, the sections were fixed in 4\% PFA and washed with PBS. Sections were mounted in a water-based mounting medium (Electron Microscopy Sciences) and observed with an Axiovert 200 microscope (Zeiss).

Electrophysiological recording. $\mathrm{Ca}^{2+}$ channel currents $\left(I_{C a}\right)$ or GIRK channel currents $\left(I_{\text {GIRK }}\right)$ were recorded using the whole-cell patch-clamp technique (Hamill et al., 1981). Patch electrodes were fabricated from 8520 patch glass $(1.65 \mathrm{~mm}$ outer diameter, $1.28 \mathrm{~mm}$ inner diameter; Warner Instruments) using a model P-97 micropipette puller (Sutter Instrument). The patch electrodes were coated with Sylgard 184 (Dow Corning) and fire-polished to a final resistance of $\sim 1.5-2 \mathrm{M} \Omega$ when filled with the pipette solution described below. The cell membrane capacitance was cancelled, and series resistance was compensated ( $>85 \%$ for both prediction and compensation; lag set to $10 \mu \mathrm{s}$ ) with an Axopatch 200B patch-clamp amplifier (Molecular Devices). The bath was grounded by an $\mathrm{Ag} / \mathrm{AgCl}$ pellet connected via a $0.2 \mathrm{M} \mathrm{NaCl} /$ agar bridge. Voltage protocol generation and data acquisition were performed using custom-designed software (S5) on a Macintosh G4 computer (Apple Computer) equipped with an ITC-18 data acquisition interface (InstruTECH). Current traces were filtered at $2 \mathrm{kHz}(-3 \mathrm{~dB})$ using a four-pole, low-pass Bessel filter, digitized at $10 \mathrm{kHz}$ with a 16-bit analogto-digital converter in the ITC-18 data acquisition interface, and stored on the computer for later analyses. All drugs and control solution were applied to single neurons via a custom-designed, gravity-driven perfusion system. A fused silica gas chromatography column at the end of the perfusion system was connected to seven parallel columns of the same diameter. Drug application was started by switching the control external solution to a drug solution to avoid flow-induced artifact until the desired test solution was applied. All recordings were performed at room temperature $\left(21-24^{\circ} \mathrm{C}\right)$.

Solutions and chemicals. For recording $I_{C a}$, patch pipettes were filled with an internal solution containing $120 \mathrm{~mm} \mathrm{~N}$-methyl-D-glucamine, 20 mm tetraethylammonium hydroxide (TEA-OH), 11 mm EGTA, $10 \mathrm{~mm}$ HEPES, $1 \mathrm{~mm} \mathrm{CaCl}_{2}$, 4 mM MgATP, $0.1 \mathrm{~mm} \mathrm{M} \mathrm{Na} \mathrm{m}_{2} \mathrm{GTP}$, and $14 \mathrm{~mm}$ Tris creatine phosphate (300 mOsm, $\mathrm{pH} 7.2$, with methanesulfonic acid). External recoding solution consisted of $140 \mathrm{~mm}$ methanesulfonic acid, $145 \mathrm{~mm}$ TEA-OH, $10 \mathrm{~mm}$ HEPES, $10 \mathrm{~mm}$ glucose, $10 \mathrm{~mm} \mathrm{CaCl}_{2}$, and 0.3 $\mu \mathrm{M}$ TTX (325 mOsm, pH 7.4, with TEA-OH). For recording $I_{\text {GIRK }}$, the pipette solutions contained $135 \mathrm{~mm} \mathrm{KCl,} 11 \mathrm{~mm}$ EGTA, $1 \mathrm{~mm} \mathrm{CaCl}_{2}, 2$ mM $\mathrm{MgCl}_{2}, 10 \mathrm{~mm}$ HEPES, $4 \mathrm{~mm}$ MgATP, $0.3 \mathrm{~mm} \mathrm{Na}_{2} \mathrm{GTP}$, and $14 \mathrm{~mm}$ Tris creatine phosphate ( $300 \mathrm{mOsm}, \mathrm{pH} 7.2$, with $\mathrm{KOH})$. The external solution contained $130 \mathrm{~mm} \mathrm{NaCl}, 5.4 \mathrm{~mm} \mathrm{KCl}, 10 \mathrm{~mm}$ HEPES, $10 \mathrm{~mm}$ $\mathrm{CaCl}_{2}, 0.8 \mathrm{~mm} \mathrm{MgCl}_{2}, 15 \mathrm{~mm}$ glucose, $15 \mathrm{~mm}$ sucrose, and $0.3 \mu \mathrm{M}$ TTX (325 mOsm, pH 7.4, with $\mathrm{NaOH}$ ). Sodium acetate (C2), sodium propionate $(\mathrm{C} 3)$, and $(R)-(-)$-3-hydroxybutyric acid $(\mathrm{BHB})$ were purchased from Sigma-Aldrich; TTX was purchased from Abcam Biochemicals; Bordetella pertussis holotoxin (PTX) was purchased from List Biological Laboratories. Stock solutions for C2, C3, and BHB were prepared in distilled water and diluted in the external solution to their final concentration before use, except for $10 \mathrm{~mm}$ working concentration, which was dissolved directly in external solution. Osmolality of external solutions was adjusted to a similar level as drug solution with sucrose. There were no severe $\mathrm{pH}$ changes in external solutions caused by SCFA working concentrations ( $\mathrm{pH} 7.45$ for $10 \mathrm{~mm} \mathrm{C2}, \mathrm{pH} 7.43$ for $10 \mathrm{~mm} \mathrm{C3,} \mathrm{pH} 7.4$ for $10 \mathrm{~mm})$.

Intranuclear injection of $c D N A s$. Vectors were directly injected into the nucleus of dissociated neurons as described previously (Ikeda, 2004; Lu et al., 2009). Briefly, injection of EGFP-labeled FFA cDNAs was performed with an Eppendorf FemtoJet microinjector and 5171 micromanipulator (Eppendorf) using an injection pressure and duration of 160 $\mathrm{hPa}$ and $0.3 \mathrm{~s}$, respectively. Vectors were diluted in TE buffer (10 mM Tris,
$1 \mathrm{~mm}$ EDTA, pH 7.4) to a final concentration of $5 \mathrm{ng} / \mu \mathrm{l}$. After injection, the neurons were incubated overnight at $37^{\circ} \mathrm{C}$. Expression of EGFP allowed identification of successfully injected neurons the following day.

Live-cell bioluminescence resonance energy transfer (BRET)-based assay. Human embryonic kidney (HEK) 293 cells (ATCC) were plated $\left(1 \times 10^{6}\right.$ cells per well) on 6-well plates in MEM supplemented with 10\% FBS, $1 \%$ penicillin-streptomycin. Cells were incubated for $6-8 \mathrm{~h}$ in a mixture of $200 \mathrm{ng}$ cAMP sensor YFP-Epac-RLuc (CAMYEL) cDNA, 60 ng empty vector (pCI), or rFFA3 cDNA and $10 \mu$ l Lipofectamine 2000 (Invitrogen) per well. Approximately 17-18 h after transfection, HEK293 cells were harvested with TrypLE Express (Invitrogen ) and washed in Dulbecco's PBS with $\mathrm{Ca}^{2+}$ and $\mathrm{Mg}^{2+}$ before loading onto black 96-well microplates (Berthold). Emission intensity after h-coelenterazine injection (5 $\mu \mathrm{M}$; Nanolight Technology) was measured using a Tristar LB941 luminometer (Berthold) by MikroWin 2000 acquisition software (Berthold). Net BRET was calculated from the light intensity measured alternately from donor and acceptor channels at $1 \mathrm{~s}$ intervals using the emission filters $460 / 60 \mathrm{~nm}$ and 542/27 nm, respectively (Semrock).

Transfection. For heterologous expression, HeLa cells (ATCC) were cultured in MEM supplemented with $10 \% \mathrm{FBS}, 1 \%$ penicillin-streptomycin on poly-L-lysine-coated dishes. Cells were transfected with $0.5 \mu \mathrm{g}$ EGFP-labeled FFA cDNAs using Lipofectamine 2000 (Invitrogen).

Data analysis and statistics. Current traces were analyzed using Igor Pro, version 6 (WaveMetrics). $I_{C a}$ amplitude was measured isochronally $10 \mathrm{~ms}$ after the initiation of a test pulse to $10 \mathrm{mV}$. The peak of $I_{\text {GIRK }}$ was taken $5 \mathrm{~ms}$ after the start of the ramp. The percentage inhibition by drugs was determined using the equation $\left(\mathrm{I}_{\text {con }}-\mathrm{I}_{\text {drug }}\right) / \mathrm{I}_{\text {con }} \times 100$, where $\mathrm{I}_{\text {con }}$ and $\mathrm{I}_{\text {drug }}$ are the $I_{\mathrm{Ca}}$ amplitude before and after drug application, respectively. Concentration-response curves (CRCs) were fit using nonlinear regression to a three-parameter logistic equation (fixed slope). Net BRET was calculated as $A / D-d$, where $A$ is the acceptor channel intensity, $D$ is the donor channel intensity, and $d$ is the background or spectral overlap (i.e., $A / D$ for donor alone). Statistical tests and curve fitting were performed with GraphPad Prism 6 for Mac OS X (GraphPad Software). All data are expressed as mean \pm SEM unless otherwise stated. Statistical significance between two groups was determined using unpaired Student's $t$ tests with Welch's correction. Multiple comparisons were performed with a one-way ANOVA followed by Newman-Keuls or Holm-Sidak's multiple-comparison test as indicated. $p<0.05$ was considered significant.

\section{Results}

\section{Endogenous G-protein signaling mechanisms of} heterologously expressed FFAs in sympathetic neurons

Previous work (Kimura et al., 2011) demonstrated physiological responses mediated by natively expressed FFA3 in mouse SCG neurons. However, our initial attempts to observe $\mathrm{Ca}^{2+}$ channel modulation after SCFA application in rat SCG neurons proved unsuccessful (see below). Thus, to determine whether FFAs can couple to neuronal $\mathrm{Ca}^{2+}$ channels, we heterologously expressed mouse FFAs in rat sympathetic SCG neurons and clonal cells. HeLa cells were transfected with EGFP-labeled mFFA3 or mFFA2 constructs to compare the cellular localization in the cell line with sympathetic neurons. Fluorescence was localized primarily in the interior of HeLa cells, possibly in internal membranes, rather than concentrating at the plasma membrane (Fig. $1 \mathrm{Ai}, \mathrm{Bi}$ ). Nuclear injection of the same constructs in dissociated rat SCG neurons resulted in fluorescence within the cytoplasm and "rim staining" suggestive of plasma membrane localization (Fig. 1Aii,Bii). Interestingly, fluorescent puncta adjacent to the plasma membrane were observed in the SCG neurons. Similar structures were previously observed in SCG neurons expressing fluorescently tagged $\mathrm{Na}^{+}$ channels (Schofield et al., 2008). The structure being labeled and significance of this pattern remain unclear.

$I_{C a}$ time courses and traces were recorded from mFFA3 or mFFA2 microinjected sympathetic SCG neuron (Fig. 1C,D). $I_{C a}$ 
A mFFA3-EGFP
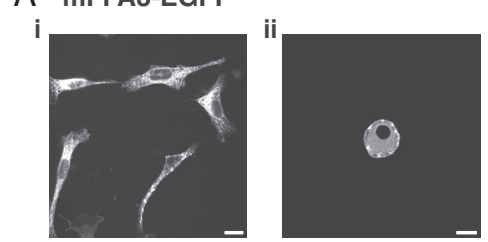

C

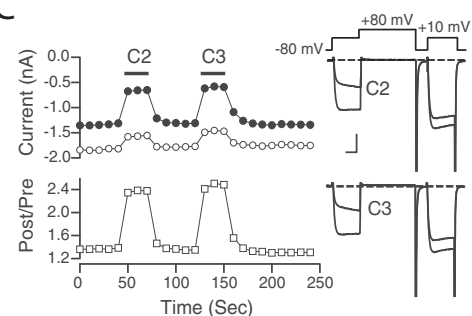

$\mathrm{E}$

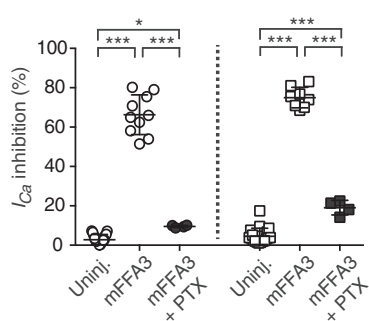

B

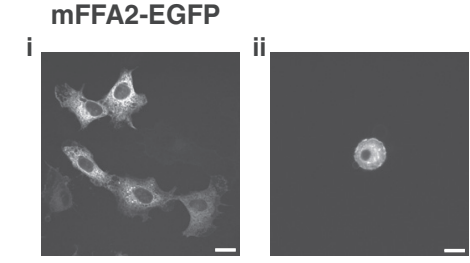

D

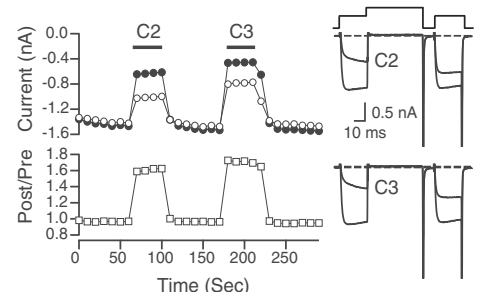

$\mathrm{F}$

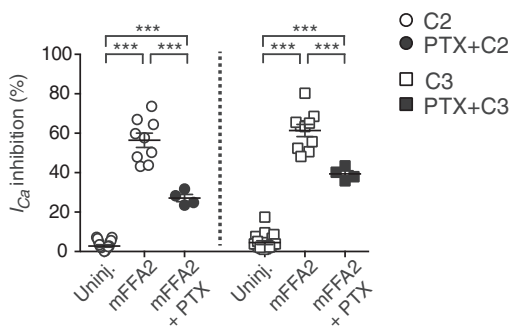

Figure 1. Modulation of $I_{C a}$ by SCFAs in rat SCG neurons heterologously expressing FFAs. $A, B$, Confocal images of mouse FFA3-EGFP and FFA2-EGFP constructs expressed in HeLa cells (Ai,Bi) and SCG neurons (Aii,Bii). Scale bar, $20 \mu$ m. C, D, Time courses of $I_{C a}($ left) and superimposed current traces (right) evoked with the double-pulse voltage protocol (inset) from mFFA3-EGFP (C) and mFFA2-EGFP (D) nuclear-injected SCG neurons. The $I_{C a}$ amplitude generated by the prepulse (filled circles) and postpulse (open circles) is plotted. Facilitation ratio was calculated as the ratio of the postpulse to prepulse $I_{C a}$ amplitude (open squares). The horizontal bars indicate the duration of $\mathrm{C} 2(1 \mathrm{~mm})$ or $\mathrm{C} 3(1 \mathrm{~mm})$ application. Calibration: $0.5 \mathrm{nA}, 10 \mathrm{~ms} . \boldsymbol{E}, \boldsymbol{F}, I_{C a}$ inhibition produced by $\mathrm{C} 2(n=9, n=10)$ or $\mathrm{C} 3(n=8, n=10)$ from each cell expressing mFFA3 $(\boldsymbol{E})$ or mFFA2 $(\boldsymbol{F})$ is represented as individual points in the dot plot graphs. Filled circles or squares on graphs indicate PTX-pretreated groups $(a l l n=4)$ for overnight. Lines on graphs indicate the mean \pm SEM for each group. The uninjected group, $n=19 .{ }^{*} p<0.05$ (one-way ANOVA followed by Newman-Keuls multiple-comparison test). ${ }^{* * *} p<0.001$ (one-way ANOVA followed by Newman-Keuls multiple-comparison test).

was evoked at $0.1 \mathrm{~Hz}$ with a double-pulse voltage protocol (Elmslie et al., 1990) consisting of a test pulse to $+10 \mathrm{mV}$ (the "prepulse") followed by a strong depolarizing step to $+80 \mathrm{mV}$, a brief return to $-80 \mathrm{mV}$, and second identical test pulse to +10 $\mathrm{mV}$ (the "postpulse") in solutions designed to isolate $I_{C a}$ (see Materials and Methods). Prepulse amplitude (closed circles), postpulse amplitude (open circles), and the facilitation ratio (open squares), defined as the ratio of the postpulse to prepulse amplitude (post/pre) were plotted. Facilitation ratio was used as a metric for voltage-dependent $\mathrm{Ca}^{2+}$ channel inhibition mediated by G $\beta \gamma$ subunits (Ikeda, 1991, 1996). Heterologously expressed mFFA3 efficiently coupled to endogenous G-proteins in SCG neurons and modulated natively expressed $\mathrm{N}$-type $\left(\mathrm{Ca}_{\mathrm{v}} 2.2\right) \mathrm{Ca}^{2+}$ channels after external application of either $\mathrm{C} 2$ or $\mathrm{C} 3$ (Fig. 1C). Expression of mFFA2 also produced robust $I_{C a}$ inhibition during $\mathrm{C} 2$ or $\mathrm{C} 3$ application (Fig. $1 D$ ). The $I_{C a}$ modulation displayed two signature properties of voltage-dependent $I_{C a}$ inhibition mediated via $G \beta \gamma$ subunits: (1) a slowing of activation kinetics in the prepulse; and (2) a partial relief of inhibition after a depolarizing conditioning pulse (Ikeda, 1996; Ikeda and Dunlap, 1999). Figure 1E, F summarizes percentage inhibition of prepulse $I_{C a}$ by $\mathrm{C} 2$ or $\mathrm{C} 3$ in mFFAsexpressing SCG neurons. Compared with control groups (uninjected), heterologous expression of mFFAs produced robust inhibition of $I_{C a}(\mathrm{mFFA3} ; 66.3 \pm 3.2 \%$ and $75.0 \pm 1.9 \%$, mFFA2; $56.4 \pm 3.6 \%$ and $61.4 \pm 3.1 \%$ by C2 and C 3 , respectively). Although FFA 3 and FFA2 share endogenous ligands, their G-protein signaling mechanisms are reported to be different. FFA3 couples exclusively to the Bordetella pertussis toxin (PTX)sensitive $\mathrm{G} \alpha_{\mathrm{i} / \mathrm{o}}$ family, whereas FFA2 couples to both $\mathrm{G} \alpha_{\mathrm{i} / \mathrm{o}}$ and PTX-insensitive $\mathrm{G} \alpha_{\mathrm{q} / 11}$ (Brown et al., 2003; Le Poul et al., 2003). In agreement with previous reports, $I_{C a}$ inhibition by SCFAs was greatly reduced by PTX pretreatment in mFFA3-expressing SCG neurons (Fig. 1E), whereas a substantial PTX-insensitive component remained $(27.1 \pm 1.8 \%$ and $39.4 \pm 1.6 \%$ by $\mathrm{C} 2$ and C3, respectively) in mFFA2-expressing SCG neurons. The residual current inhibition was largely voltage-independent and presumably mediated by a $\mathrm{G} \alpha_{\mathrm{q} / 11}$-related pathway (Fig. $1 F$ ).

Next, we examined the potencies of SCFAs to activate FFAs in the heterologous expression system. CRCs for $I_{C a}$ inhibition were generated from FFAexpressing SCG neurons by applying sequentially increasing or decreasing amounts of agonist (Fig. 2A). The rapid, reversible, and nondesensitizing nature of the SCFAs response facilitated generation of CRCs (Fig. 2B). In SCG neurons expressing either mouse or rat FFA3, C3 was more potent $\left(\mathrm{EC}_{50}=24 \pm 1.1\right.$ and $10 \pm$ $1.2 \mu \mathrm{M}$, respectively) than $\mathrm{C} 2\left(\mathrm{EC}_{50}=\right.$ $374 \pm 1.2$ and $797 \pm 1.3 \mu \mathrm{M}$, respectively) but had similar efficacies $(\sim 60-65 \%$ maximal $I_{C a}$ inhibition). On the other hand, C2 and C3 showed similar potencies in FFA2-expressing SCG neurons $\left(\mathrm{EC}_{50}=200 \pm 1.1\right.$ and $120 \pm 1.1 \mu \mathrm{M}$ for mFFA2, $\mathrm{EC}_{50}=988 \pm 1.3$ and $1404 \pm 1.2$ $\mu \mathrm{M}$ for rFFA2, respectively) and displayed slightly lower efficacies $(\sim 60 \%)$ compared with FFA3. The order of agonist potency (FFA3 C3 $\gg \mathrm{C} 2$; FFA2 C3 $\approx \mathrm{C} 2$ ) agreed well with previous estimates based on in vitro assays (Brown et al., 2003; Le Poul et al., 2003).

\section{Abundant FFA3 transcript in sympathetic ganglia}

The lack of an overt native response to C2 and C3 in rat SCG neurons (Fig. 1E,F; uninjected) led us to examine FFA3 and FFA2 transcript levels in several tissues. We performed RT-PCR analysis in several rat sympathetic ganglia and a panel of rat tissues, including whole brain, sensory ganglia, adrenal gland (AG), and white adipose tissue (WAT). The mRNA from both sympathetic and sensory ganglia was derived from enzymatically isolated neurons rather than whole ganglia to reduce the contribution of non-neuronal cells. Figure $3 A$ illustrates $\mathrm{rFFA} 3$ and rFFA2 RT-PCR products for a variety of rat tissues. Abundant rFFA3 transcript was detected in all tested sympathetic ganglia, including SCG, SG, CSMG, and MPG. In contrast, brain, DRG, nodose, AG, and WAT showed little or no visible band corresponding to rFFA3 transcript. Compared with rFFA3, expression of rFFA2 transcript was not prominent in sympathetic ganglia samples, except CSMG. WAT was used as a positive control for detecting rFFA2 transcript expression (Brown et al., 2003; Hong et al., 2005). Amplification of tyrosine hydroxylase or $\beta$-actin served as indices of catecholaminergic neuron or general cellular (i.e., housekeeping gene) mRNA quantity, respectively. TaqMan qRT-PCR analyses were performed to quantify the relative ex- 
A
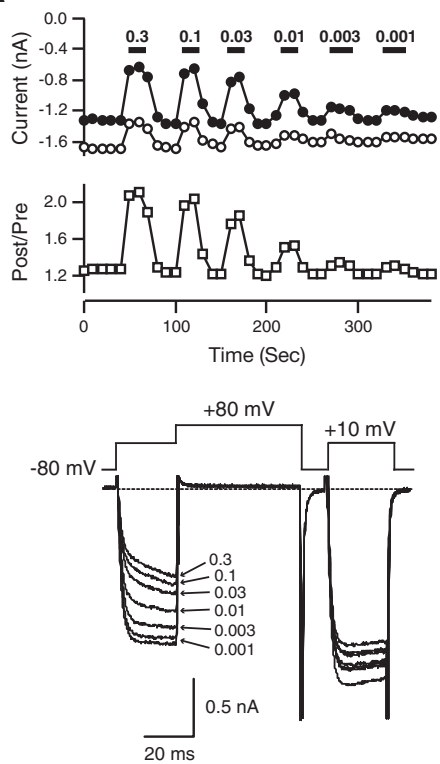

B

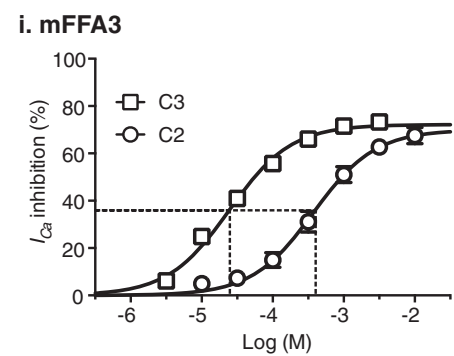

iii. rFFA3

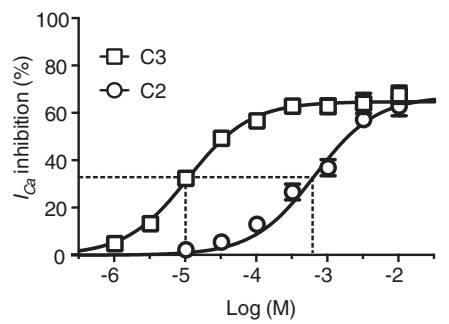

ii. $\mathrm{mFFA2}$

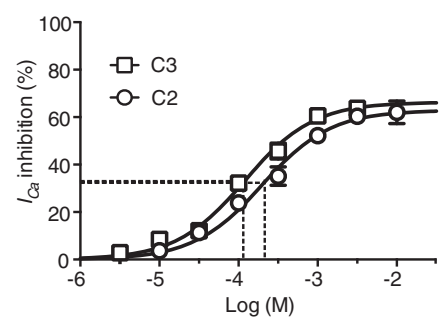

iv. rFFA2

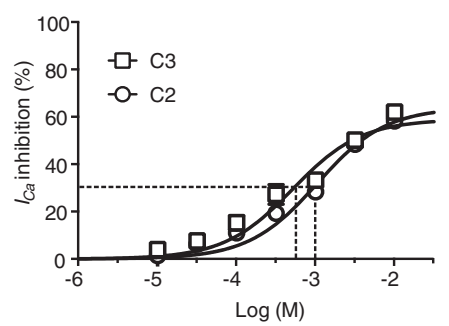

Figure 2. Concentration-response curves of heterologously expressed FFAs in SCG neurons by SCFAs. $A$, Time course (top) and superimposed current traces (bottom) of $I_{C a}$ amplitude inhibition by serial $C 3$ application in heterologously rFFA3-expressed SCG neurons. The horizontal bars represent the duration of drug application. Superimposed current traces are obtained from time points showing maximal $I_{C a}$ inhibition during application of each indicated concentration (millimolar). $B, S C F A$ responses at each concentration were normalized to baseline of $I_{C a} u$ using the equation $\left(I_{\text {con }}-I_{\text {drug }}\right) I_{\text {con }} \times 100$, where $I_{\text {con }}$ and $I_{\text {drug }}$ were the $I_{c a}$ amplitudes before and after drug application, respectively. Solid lines represent nonlinear regression least-square fits (using GraphPad Prism) of experimental points to a 3 parameter logistic equation: $y=b o t t o m+($ top - bottom $) /\left(1+10^{\log E 550}-x\right)$, where $y$ is $I_{C a}$ inhibition $(\%)$, top is the maximal inhibition, $E C_{50}$ is the half-maximal concentration, and $x$ is drug concentration. For these data, bottom was constrained to 0 . Dashed horizontal lines on each curve represent $E C_{50}$ of the $C 2$ (open circles) or $C 3$ (open squares) in mouse FFA3 (Bi), rat FFA3 (Biii), mouse FFA2 (Bii), and rat FFA2 (Biv) expressed SCG neurons. All data points are presented as mean \pm SEM and averaged from at least five different cells.

A

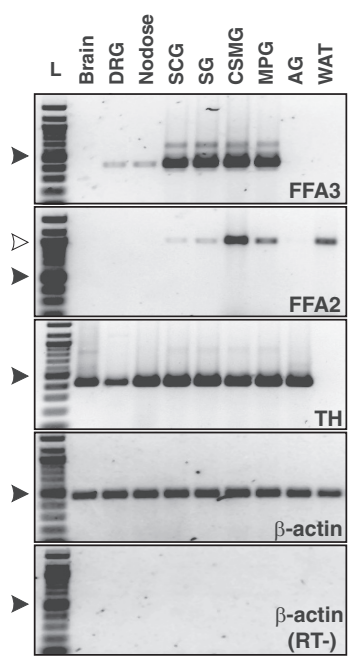

B
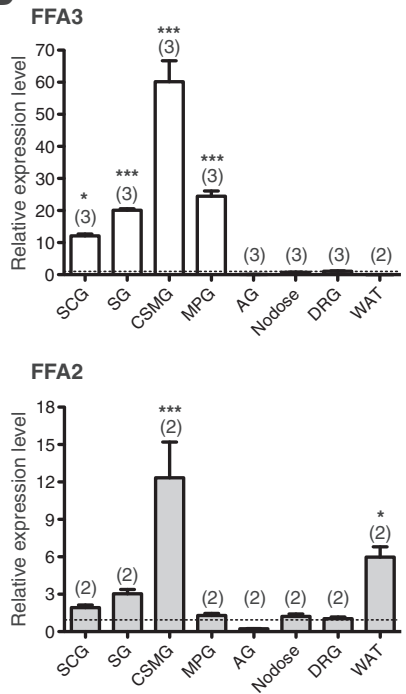

C
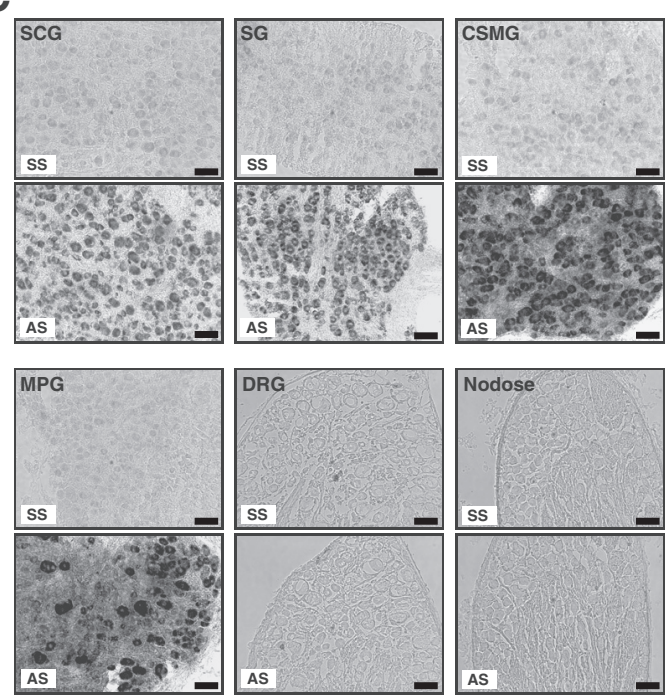

Figure 3. FFAs transcript expression. $A$, Conventional RT-PCR analysis of mRNA encoding FFA3 and FFA2 in a variety of rat tissues. The resultant PCR products were separated and visualized on $1.5 \%$ agarose gel. FFA3 and FFA2 indicate RT-PCR products generated from primers sets coding for FFA3 (predicted size $425 \mathrm{bp}$ ) and FFA2 ( $993 \mathrm{bp}$ ), respectively. Amplification of tyrosine hydroxylase (TH, $422 \mathrm{bp}$ ) and $\beta$-actin (492 bp) served as indices of catecholaminergic neurons and general cellular mRNA integrity, respectively. Amplification of $\beta$-actin in which reverse transcriptase was omitted (RT -) was used to assess potential gDNA contamination. L, 100 bp ladder; Brain, rat whole brain; Nodose, nodose ganglia. Filled and opened arrowheads represent 500 bp and 1 kbp size markers, respectively. $\boldsymbol{B}$, Relative FFA3 (top) and FFA2 (bottom) transcript expression in rat tissues assessed by qRT-PCR. Relative expression of FFAs in each tissue is obtained from the formula $2^{-\Delta \Delta C_{T}}$ (detailed in Materials and Methods). The point 1.0 on the $y$-axis (dotted line) indicates the expression level of FFAs in DRG neurons $\left(2^{-\Delta \Delta G_{T}}=1\right)$. The averaged $C_{T}$ values were obtained from triplicate of each $P C R$. The number of cDNA preparation is indicated in parentheses on the graph. Data are presented as mean \pm SEM. To compare groups, a one-way ANOVA followed by Holm-Sidak's multiple-comparison test (control group: DRG) was used. ${ }^{*} p<0.05$. ${ }^{* * *} p<0.001$. C, FFA3 transcript localization in rat sympathetic ganglia is determined by in situ hybridization using a DIG-labeled antisense FFA3 probe. Sensory ganglia sections (DRG and nodose) were used as negative control. SS, sense probe; AS, antisense probe. Scale bar, $50 \mu \mathrm{m}$.

pression levels of rFFA3 and rFFA2 transcripts. The rFFA3 transcript in sympathetic ganglia was higher than other tested tissues (Fig. 3B, top; one-way ANOVA, $p<0.05$ ). In particular, the CSMG displayed the highest level, whereas little or no expression of rFFA3 transcript was detected in AG, nodose ganglion, DRG, or WAT. At present, FFA3 expression level in WAT is controversial with literature values ranging from the highest levels detected to virtually zero (Brown et al., 2003; Xiong et al., 2004; Hong et 
A scG

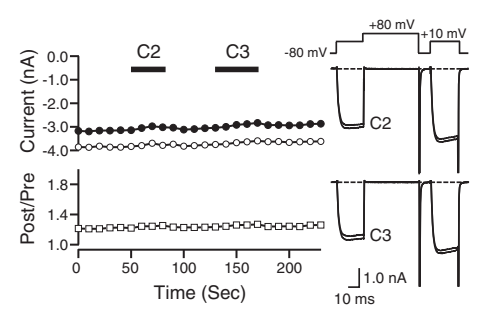

C csmg

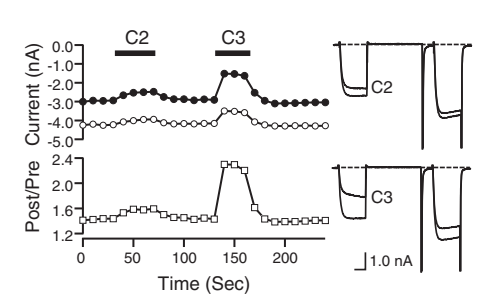

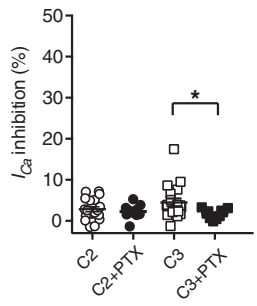

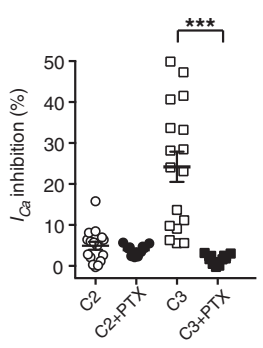

B sG
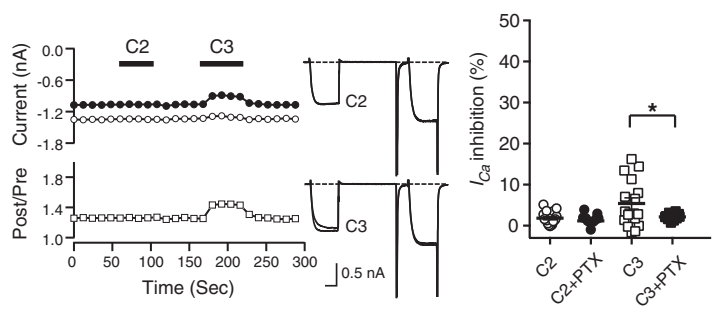

\section{MPG (SN)}

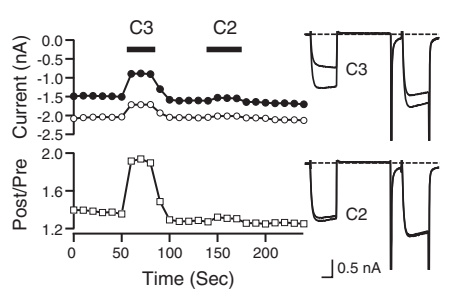

Figure 4. SCFA-induced $I_{C a}$ modulation via natively expressed FFA3 in sympathetic neurons. $A-D$, Left, Time courses and superimposed current traces of $I_{C a}$ inhibition recorded during application of $C 2(1 \mathrm{~mm})$ or $C 3(1 \mathrm{~mm})$ in enzymatically dissociated SCG $(\boldsymbol{A})$, SG $(\boldsymbol{B})$, CSMG $(\boldsymbol{C})$, and sympathetic MPG (D) neurons. Horizontal bars represent the period of $C 2$ and C3 application. Right, $I_{C a}$ inhibition produced by C2 (open circles) or C3 (open squares) from each sympathetic neuron is represented as individual points in the dot plot graph. Filled circles and squares on graphs represent overnight-incubated sympathetic neurons in culture media (MEM/10\% FBS) containing PTX ( $500 \mathrm{ng} / \mathrm{ml}$ ). Solid lines on the graphs indicate each mean \pm SEM. To compare between control and PTX-treated group, unpaired $t$ test with Welch's correction was used. ${ }^{*} p<0.05$. ${ }^{* * *} p<0.001$. Horizontal calibration: $\boldsymbol{A}-\boldsymbol{D}$ current traces, $10 \mathrm{~ms}$.

al., 2005; Zaibi et al., 2010). Our results suggest a negligible level of FFA3 transcript in WAT. As a positive control for WAT mRNA quantity and quality, the abundance of FFA2 transcript expression in WAT was determined and found to be consistent with previous reports (Fig. 3B, bottom; one-way ANOVA, $p<0.05$ ). High levels of rFFA2 transcript, exceeding those found in WAT, were detected in CSMG consistent with the conventional RTPCR data shown in Figure $3 A$.

To examine the cellular distribution of FFA3 transcript in sympathetic ganglia, in situ hybridization was performed using specific probes targeted to the first and second exon junction. Intense FFA3 hybridization reaction product was seen in neuronal somata in antisense probe (AS) treated sympathetic ganglia sections (Fig. 3C). The strongest signal was observed in CSMG sections, which correlated well with qRT-PCR analysis results (Fig. 3B). The MPG is unique among autonomic ganglia in that both sympathetic and parasympathetic neurons reside within the same ganglion capsule (Keast, 1995). Cell diameters in the MPG neurons are bimodally distributed with the larger diameter population being comprised of tyrosine hydroxylase containing sympathetic neurons (Zhu et al., 1995). The preferential staining of larger cells in the MPG sections suggests that FFA3 transcript is enriched (if not restricted to) the sympathetic neuron subpopulation. In contrast to sympathetic neurons, neither DRG nor nodose ganglion sections revealed an overt hybridization signal (Fig. $3 C$ ). Attempts to demonstrate specific FFA3 protein expression by immunostaining and Western blots with both commercial and custom-designed polyclonal antibodies were unsuccessful (data not shown).

SCFA-induced $I_{C a}$ modulation via natively expressed FFA3 in sympathetic neurons

To investigate functional consequences of native FFA3 activation, we examined whether $I_{C a}$ was modulated by SCFA application in enzymatically dissociated sympathetic ganglion neurons. Although abundant FFA3 transcript has been reported in mouse
SCG (Kimura et al., 2011), miniscule $I_{C a}$ inhibition was produced by C3 (1 mM) application in dissociated rat SCG neurons (Fig. $4 A$; see also Fig. $1 E, F$ ). In SG neurons, mean $I_{C a}$ amplitude was modestly inhibited (mean $5.4 \%$ ) by C3 with a large coefficient of variation (104\%) (Fig. 4B). In CSMG and sympathetic MPG neurons, application of $\mathrm{C} 3$ dramatically inhibited $I_{C a}$ in a subset of neurons, which displayed properties typical of voltagedependent $I_{C a}$ inhibition (Ikeda, 1991, 1996) (Fig. 4C,D). The mean $I_{C a}$ inhibition was $24 \pm 3 \%$ and $23 \pm 3 \%$ in CSMG and sympathetic MPG neurons, respectively. There was substantial cell-to-cell response variation as reflected by coefficients of variation of $\sim 60 \%$ for both preparations. The presence of lowvoltage activated $I_{C a}\left(\mathrm{LVA}-I_{C a}\right)$ was used to discriminate sympathetic from parasympathetic MPG neurons in the dissociated neuron preparation (Zhu et al., 1995; Lee et al., 2002). $I_{C a}$ in parasympathetic MPG (PS-MPG) neurons (i.e., those lacking LVA- $I_{C a}$ ) was not affected by SCFA application (mean inhibition $0.8 \pm 0.5 \%)$. In all of these preparations, application of C2 (1 $\mathrm{mM}$ ) was without significant effect.

To examine the class of heterotrimeric G-protein involved in SCFA-mediated $I_{C a}$ inhibition, sympathetic neurons were preincubated with PTX (500 ng/ml) 15-17 h before recording. $I_{\mathrm{Ca}}$ inhibition by SCFAs was abolished in all PTX-preincubated sympathetic neurons (Fig. 4A-D; unpaired $t$ test with Welch's correction). This result is consistent with $I_{\mathrm{Ca}}$ modulation occurring primarily via FFA3 in CSMG neurons despite the detection of appreciable FFA2 message in this ganglion (Fig. 3B, bottom). It also diminishes the likelihood that Olfr78, a $\mathrm{G} \alpha_{\mathrm{S}}$-coupled GPCR that also responds to SCFAs (Pluznick et al., 2013) and may be expressed in sympathetic neurons (Weber et al., 2002), contributes to $I_{C a}$ modulation. Together, these data represent the first demonstration of $I_{C a}$ inhibition mediated by SCFA application in sympathetic neurons. In agreement with the qRT-PCR and in situ hybridization data, the magnitude of inhibition was greater in prevertebral (CSMG, MPG) versus paravertebral (SCG, SG) sympathetic neurons. 
A

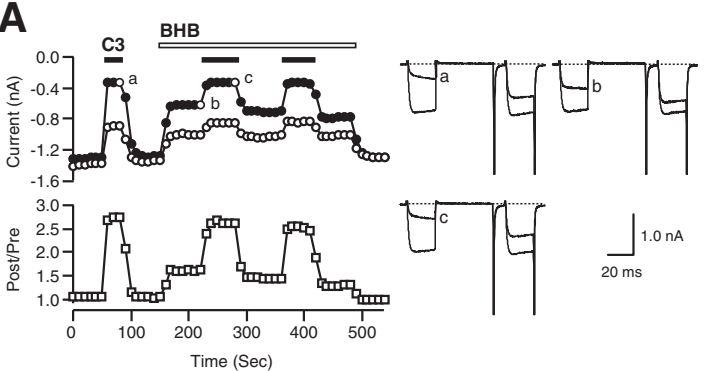

C

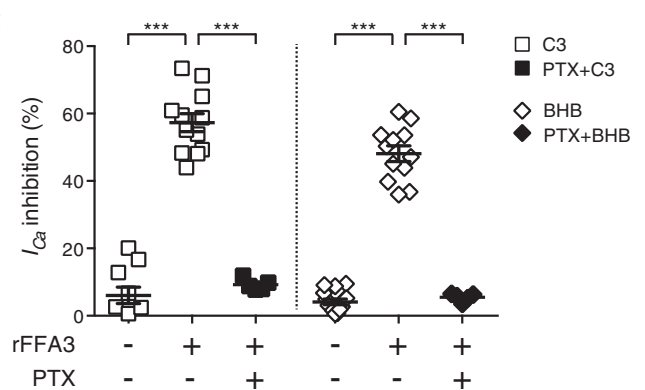

B

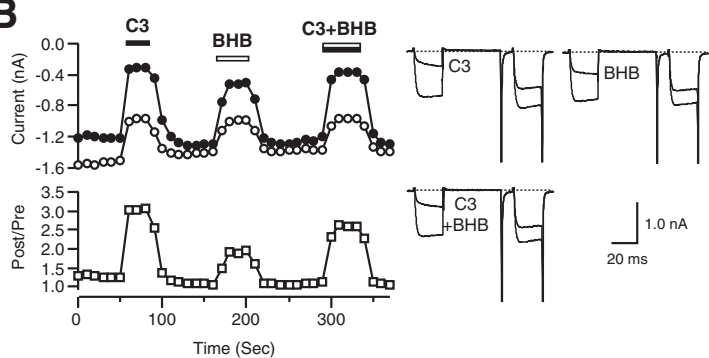

D

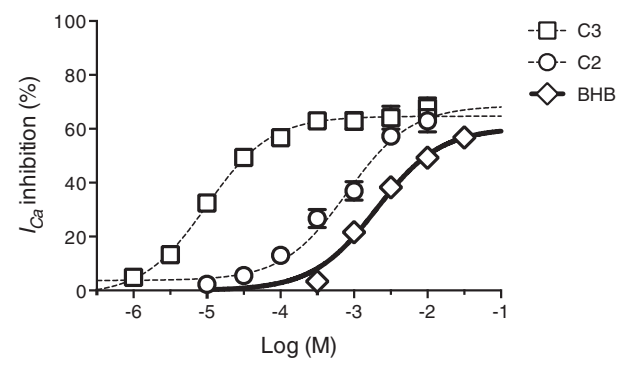

Figure 5. BHB modulates $I_{C a} \cdot A$, Time course and superimposed current traces of $I_{C a}$ amplitude inhibition by application of $\mathrm{C} 3(1 \mathrm{~mm})$ alone and application in the presence of $B H B(10 \mathrm{~mm})$ in heterologously rFFA3 expressed $S C G$ neurons. Superimposed current traces are obtained at different time points during drug application (labeled as a-c). $\boldsymbol{B}$, Time course and superimposed current traces of $I_{C a}$ amplitude during sequential application of $\mathrm{C} 3(1 \mathrm{~mm}), \mathrm{BHB}(10 \mathrm{~mm})$, and $\mathrm{C} 3+\mathrm{BHB}(1 \mathrm{~mm}+10 \mathrm{~mm})$ in heterologously rFFA3 expressed $\mathrm{SCG}$ neurons. Horizontal filled and opened bars represent the period of $\mathrm{C} 3$ and BHB application, respectively. $C, I_{C}$ inhibition produced by $\mathrm{C}$ (squares) or BHB (diamonds) from SC $G$ neuron-expressing rFFA3 are represented as individual points in the dot plot graph. Filled squares and filled diamonds on the graphs represent PTX-pretreated groups. Solid lines on the graphs indicate mean \pm SEM. To compare groups, a one-way ANOVA followed by Newman-Keuls multiple-comparison test was used. ${ }^{* * *} p<0.001$. D, Concentration-response curves for $I_{C a}$ inhibition by BHB $(n=5)$. Solid thick line indicates nonlinear regression fits of BHB responses generated from rFFA3-expressing SCG neurons. To compare potencies, concentration-response curves for C2 (open circles, $n=4-11$ ) and C3 (open squares, $n=6-9$ ) on rFFA3expressing neurons are represented on the graph (dashed lines).

\section{BHB, a ketone body, modulates $I_{C a}$ by acting as an agonist for FFA3}

Although SCFAs are proposed as endogenous ligands for FFA3, it is unclear whether plasma concentrations of C2 or C3 in nonruminating mammals attain sufficient levels to activate receptors on sympathetic neurons or other tissues not directly exposed to the intestinal lumen. However, $\mathrm{BHB}$, a ketone body, can reach low millimolar plasma concentrations during short-term (24-48 h) food deprivation and exceed $10 \mathrm{~mm}$ during starvation, ketoacidosis, or adherence to a ketogenic diet. Recently, BHB was proposed to be an antagonist of FFA3 (Kimura et al., 2011). To investigate the effect of $\mathrm{BHB}$ on FFA3, we examined whether application of BHB modified FFA3-mediated $I_{C a}$ inhibition in SCG neurons heterologously expressing FFA3. After $60 \mathrm{~s}$ of baseline recording, neurons were superfused with C3 (1 mM) to confirm functional expression of FFA3. After removal of C3, currents were allowed to recover to baseline amplitude and then BHB (10 $\mathrm{mM}$ ) was applied. Unexpectedly, application of $\mathrm{BHB}$ produced rapid inhibition of $I_{C a}$, revealing properties of an agonist rather than antagonist. Moreover, coapplication of $\mathrm{C} 3$ and BHB did not reduce $I_{C a}$ modulation compared with $\mathrm{C} 3$ application alone (Fig. $5 A$ ). The effects of $\mathrm{BHB}$ on $I_{\mathrm{Ca}}$ were consistent with voltagedependent inhibition based on the overt kinetic slowing in the prepulse trace and increase in the facilitation ratio during agonist-mediated inhibition. The drug application protocol depicted in Figure $5 A$ was modified in Figure $5 B$ to more clearly illustrate the agonist properties of BHB. Application of $\mathrm{BHB}$ alone produced rapid and reversible voltage-dependent $I_{C a}$ inhibition and, when combined with C3, resulted in similar amplitude and facilitation ratio changes as $\mathrm{C} 3$ application. Figure $5 \mathrm{C}$ summarizes $I_{C a}$ inhibition by $\mathrm{C} 3$ or BHB in rFFA3-expressing SCG neurons (mean $57 \pm 3 \%$ and $48 \pm 2 \%$, respectively). The mean facilitation ratio was $3.0 \pm 0.2$ and $2.5 \pm 0.2$ in the presence of $\mathrm{C} 3$ and $\mathrm{BHB}$, respectively. $I_{\mathrm{Ca}}$ modulation by both $\mathrm{C} 3$ and $\mathrm{BHB}$ was abolished by PTX pretreatment (Fig. 5C), indicating a PTXsensitive voltage-dependent G-protein-modulatory pathway for both agonists. Last, a concentration-response curve for $I_{C a}$ inhibition by $\mathrm{BHB}$ was generated from rFFA3-expressing SCG neurons (Fig. $5 D$ ) using a protocol similar to that shown in Figure $2 A$. A single application of $\mathrm{C} 3(1 \mathrm{~mm})$ preceded the $\mathrm{BHB}$ applications to confirm functional expression of FFA3. Compared with the previously tested SCFAs (C2 or C3), BHB had the lowest potency $\left(\mathrm{EC}_{50}=2.0 \pm 1.2 \mathrm{~mm}\right)$, although efficacy $(\sim 56 \%$ inhibition $)$ was similar to that of $\mathrm{C} 2$ and $\mathrm{C} 3$.

\section{Additional evidence that BHB is an agonist for FFA3}

Given the unexpected result that BHB activates FFA3, additional experiments were performed to substantiate the finding. First, we heterologously expressed rFFA3 in nodose sensory ganglion neurons to determine whether the effect of BHB on FFA3 was restricted to endogenous signaling pathways of sympathetic neurons. FFA3 transcript level in nodose neurons (Fig. 3B) was negligible, thus providing an unambiguous null background. HVA- $I_{C a}$ in rFFA3-expressing nodose ganglion neurons was inhibited by repetitive $\mathrm{BHB}$ application with overt kinetic slowing in the prepulse trace and increase in the facilitation ratio during inhibition (Fig. 6A). The mean percentage inhibition of $I_{\mathrm{Ca}}$ by either $\mathrm{C} 3$ or $\mathrm{BHB}$ in rFFA3-expressing nodose ganglion neurons is shown in Figure 6B. Second, we examined whether BHB serves as an agonist of FFA3 by activating G-protein-coupled inwardrectifying $\mathrm{K}^{+}$(GIRK) channels in HEK293 cells. GIRK channels are typically activated by $\mathrm{G} \beta \gamma$ released from $\mathrm{G} \alpha_{\mathrm{i} / \mathrm{o}} \mathrm{G}$-proteins after agonist interaction with GPCRs. The functional homomeric mutant GIRK4 S143T-EGFP (Vivaudou et al., 1997) was trans- 
A

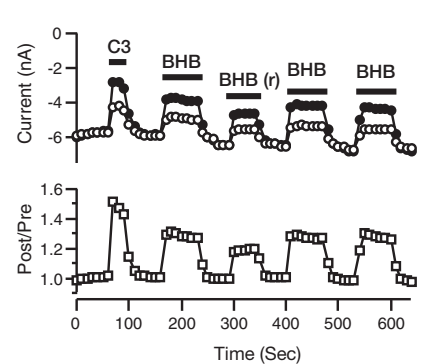

C

GIRK4 S143T-EGFP

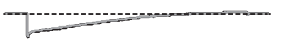

GIRK4 S143T-EGFP + rFFA3
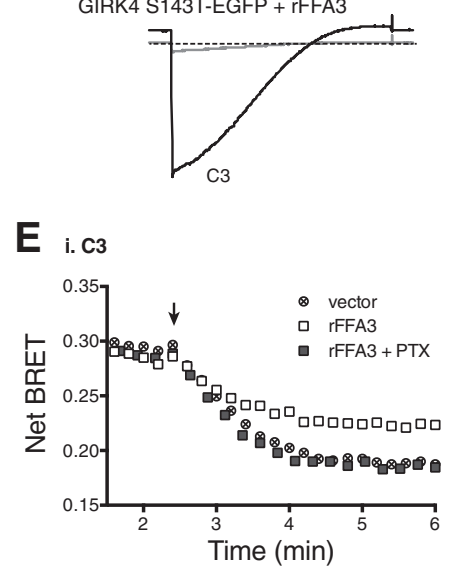
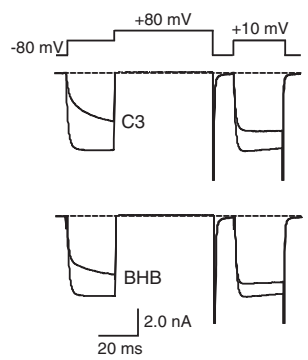

$\frac{\mathrm{ms}}{20}$
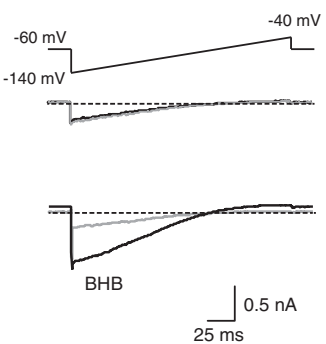

B

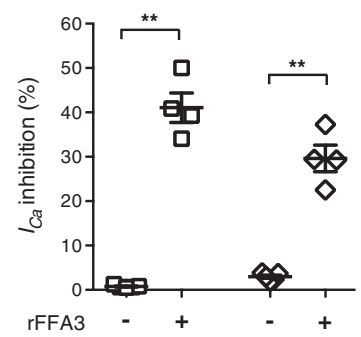

$\square \mathrm{C} 3$

$\diamond \mathrm{BHB}$

D

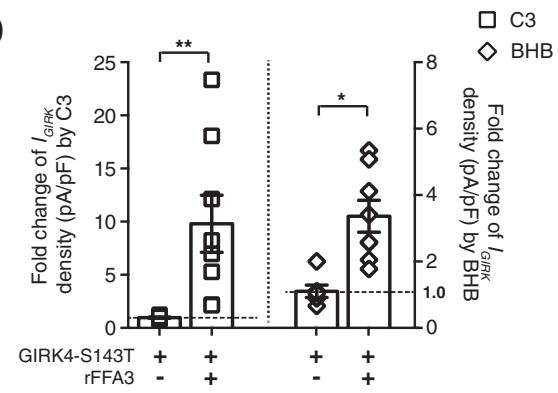

$\mathbf{F}$

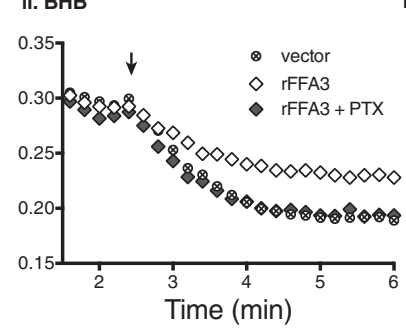

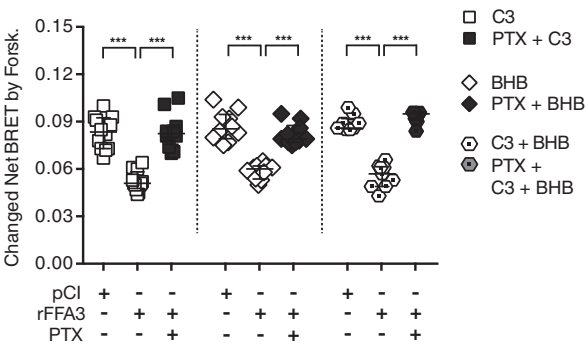

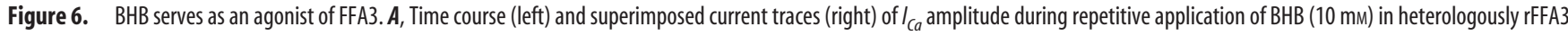
expressed nodose ganglion neurons. The horizontal bars represent the duration of either (3 or BHB application. BHB (r) indicates racemic mixture, which is ( \pm )-sodium 3-hydroxybutyrate (10 mM). $B$, Dot plots representing I ${ }_{C a}$ inhibition produced by C3 (squares) or BHB (diamonds) from rFFA3-expressed nodose ganglion neurons. ** $p<0.01$ (unpaired $t$ test with Welch's correction). $C$, Superimposed current traces from GIRK4 S143T-EGFP (top) alone or with rFFA3 (bottom) transfected HEK293 cells before (gray lines) and after application of C3 (1 mM) or BHB (10 mM). Whole-cell inwardly rectifying $I_{\text {GIRK }}$ were evoked by $200 \mathrm{~ms}$ voltage ramps from -140 to $-40 \mathrm{mV}$ from a holding potential of $-60 \mathrm{mV}$ (inset). Dashed lines on the traces indicate the zero current level. $D$, Summary graph represents the mean \pm SEM of the fold change of $I_{\text {GIRK }}$ density (pA/pF) activated by C3 (open squares) or BHB (open diamonds). ${ }^{*} p<0.05$, ${ }^{* *} p<0.01$ (unpaired $t$ test with Welch's correction). $\boldsymbol{E}$, Monitoring cAMP levels in living cells using the BRET-based sensor CAMYEL. HEK293 cells were transfected using Lipofectamine with empty vector (pCI) or rFFA3 and CAMYEL cDNA. Ei, ii, Exemplar plots of net BRET versus time after injection of substrate ( $h$-coelenterazine). The data were decimated to display every fifth point and represent the mean of two independent sample runs from the same transfection. Five minutes before addition of substrate, the transfected cells were preincubated with $1 \mathrm{~mm} \mathrm{C3} \mathrm{(Ei)} \mathrm{or} 10 \mathrm{~mm}$ BHB (Eii). Black arrows indicate injection of forskolin $(1 \mu \mathrm{M})$. A decrease in net BRET indicates an increase in intracellular cAMP concentration. HEK293 cells were incubated overnight with PTX (500 ng/ml, filled squares and diamonds) where indicated. $\boldsymbol{F}$, The change in net BRET produced by forskolin injection for cells preincubated with C3 (left), BHB (middle), or C3 + BHB together (right). The net BRET change was calculated by subtracting net BRET at 4 min after forskolin injection from the value just before injection. Solid lines on the graphs indicate mean \pm SEM. Each point represents an independent measurement from four (C $3+B H B)$ or five (C3 or BHB) separate transfections. To compare groups, a one-way ANOVA followed by Newman-Keuls multiple-comparison test was used. ${ }^{* * *} p<0.001$.

fected into the HEK293 cells either alone or together with rFFA3. GIRK currents $\left(I_{\text {GIRK }}\right)$ were elicited from a holding potential of $-60 \mathrm{mV}$ by a $200 \mathrm{~ms}$ voltage ramp from -140 to $-40 \mathrm{mV}$. In most GIRK-expressing cells, there was some tonic activation of $I_{\text {GIRK }}$ before agonist application. In the absence of rFFA3 expression, application of $\mathrm{C} 3$ or $\mathrm{BHB}$ induced negligible inward $I_{\text {GIRK }}$ (Fig. 6C, top). In the HEK293 cell coexpressing GIRK4 S143T and rFFA3, application of either $\mathrm{C} 3$ or $\mathrm{BHB}$ resulted in robust inward currents at hyperpolarized potentials that reversed polarity at $\sim-80 \mathrm{mV}$ (Fig. $6 \mathrm{C}$, bottom). Figure $6 \mathrm{D}$ summarizes the fold change of $I_{\text {GIRK }}$ density $(\mathrm{pA} / \mathrm{pF})$ induced by C3 or BHB. Last, we examined cAMP levels after forskolin stimulation of adenylate cyclase in living HEK293 cells with the BRET-based cAMP sensor, CAMYEL (Jiang et al., 2007). Five minutes before commencing luminescence measurements, agonist ( $\mathrm{C} 3$ or $\mathrm{BHB}$ ) was added to 96-well plates containing transfected cells. Net BRET was calculated from measurements of light intensity from the acceptor and donor channels after application of enzyme substrate, h-coelenterazine (benzyl coelenterazine). Forskolin $(1 \mu \mathrm{M})$ was used to stimulate adenylate cyclase and produced a robust decrease in net BRET (corresponding to an increase in intracellular cAMP concentration) in HEK293 cells. Preincubation with either C3 or BHB attenuated the forskolin-induced decrease in net BRET from rFFA3-transfected HEK293 cells (Fig. 6Ei,ii), but not in the cells transfected with an empty vector (pCI). Pretreatment of rFFA3-transfected HEK293 cells with PTX abolished the alterations produced by $\mathrm{C} 3$ or BHB. The summary of net BRET changes is shown in Figure $6 \mathrm{~F}$. When $\mathrm{C} 3$ and $\mathrm{BHB}$ were coincubated with rFFA3-expressing cells, the result was similar to when either drug was applied separately (Fig. 6F). Together, these data provide multiple convergent lines of evidence that $\mathrm{BHB}$ acts as an agonist, not an antagonist, at FFA3.

We also sought to determine whether GPR109A (PUMA-G, NIACR1, $\mathrm{HCA}_{2}$ ), a GPCR responsive to both $\mathrm{BHB}$ and niacin (Taggart et al., 2005), might participate in the observed response. Figure 7A shows that GPR109A transcript levels were barely detectable in SCG and MPG neurons, greater in the CNS, and robust in WAT as previously reported (Tunaru et al., 2003; Wise et 
al., 2003). Heterologous expression of GPR109A in SCG neurons revealed that the receptor functionally expressed and coupled to $\mathrm{Ca}^{2+}$ channels via PTXsensitive G-proteins. Voltage-dependent inhibition of $I_{C a}$ was produced by both $\mathrm{BHB}(10 \mathrm{mM})$ and niacin $(1 \mu \mathrm{M})$, in agreement with the biochemical literature, whereas C3 (1 mM) application was ineffective (Fig. 7B). Niacin applied to rFFA3expressing SCG neurons produced no overt $\mathrm{Ca}^{2+}$ current inhibition $(-0.2 \pm$ $6.6 \%, n=3)$, arguing against the possibility that rFFA3 expression upregulates endogenous GPR109A. Niacin application to uninjected SCG or sympathetic MPG neurons produced no discernible response (mean inhibition $2.8 \pm 0.6 \%, n=$ 5 , and $-1.7 \pm 0.4 \%, n=8$, respectively). From these data, we conclude that natively expressed GPR109A is unlikely to participate in BHB-mediated responses in SCG neurons.

\section{BHB modulates $I_{C a}$ via natively} expressed FFA3 in sympathetic neurons To investigate the effects of $\mathrm{BHB}$ on natively expressed FFA3, we examined $I_{\mathrm{Ca}}$ modulation by BHB in sympathetic MPG neurons. As mentioned earlier (Figs. 3 and 4), the rat MPG contains both sympathetic and parasympathetic neurons. The MPG sympathetic neurons express LVA$\mathrm{Ca}^{2+}$ channels, allowing segregation of the two populations based on electrophysiological criteria, and respond to C3 application, although with considerable variability. The MPG parasympathetic neurons appear devoid of C3 responses and thus serve as control for neurons presumably devoid of functional FFA3. Figure $8 A i$, Aii illustrates $I_{C a}$ time courses and traces recorded from enzymatically dissociated sympathetic ( $\mathrm{SN}$ ) and parasympathetic (PS) MPG neurons, respectively. In MPG sympathetic neurons, application of C3 $(1 \mathrm{~mm})$ produced $I_{\mathrm{Ca}}$ inhibition accompanied by an increase in facilitation ratio as shown previously (Fig. 4D). Subsequent application of BHB (10 $\mathrm{mm}$ ) resulted in similar $I_{C a}$ modulation demonstrating that the response seen in heterologous expression systems (Fig. 5B) recapitulates in a native setting. In contrast, MPG parasympathetic neurons displayed little response to either $\mathrm{C} 3$ or $\mathrm{BHB}$ application (Fig. 8Aii). The small inhibition produced by BHB was not accompanied by a change in facilitation ratio. Summary data for these experiments are illustrated in Figure 8B. C3 application in MPG sympathetic neurons resulted in a highly variable $I_{C a}$ inhibition (mean inhibition 20\%; coefficient of variation $72 \%$ ) that mimicked our earlier dataset(Fig. 4D). Application of BHB produced a smaller mean inhibition (12.5\%) with a large variance (coefficient of variation 55\%). The amplitude of the BHB inhibition was positively correlated with the $\mathrm{C} 3$ response (Fig. $8 \mathrm{C}$ ), supporting the interpretation that the responses arose from the same receptor. $I_{C a}$ inhibition produced by BHB normalized to the maximum $I_{C a}$ inhibition produced by $\mathrm{C} 3$ in the same sympathetic MPG neuron was $0.53 \pm 0.04$. Overnight incubation with PTX abolished the variability of $I_{C a}$ inhibition by $\mathrm{C} 3$ or $\mathrm{BHB}$, indicating that $\mathrm{G} \alpha_{\mathrm{i} / \mathrm{o}}$-coupled signaling pathways were
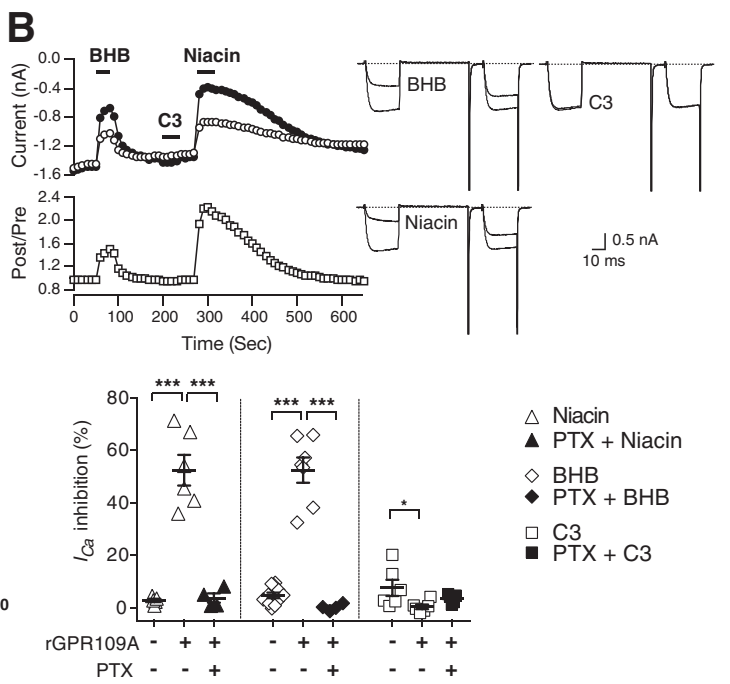

$\triangle$ Niacin

PTX + Niacin

C3

$\mathrm{PTX}+\mathrm{C3}$

Figure 7. Natively expressed GPR109A does not contribute to BHB-mediated responses in sympathetic neurons. $\boldsymbol{A}$, Top, Con-

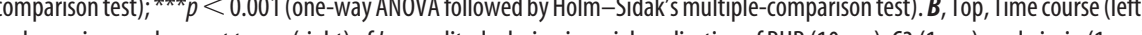
in heterologously GPR109A expressed SCG neurons. The horizontal bars represent the duration of each drug application. Bottom presented as mean \pm SEM. ${ }^{*} p<0.05$ (one-way ANOVA followed by Newman-Keuls post test.). ${ }^{* *} p<0.001$ (one-way ANOVA followed by Newman-Keuls post test.).

involved. On the other hand, neither $\mathrm{C} 3$ nor $\mathrm{BHB}$ produced $I_{C a}$ inhibition in parasympathetic neurons (Fig. $8 B$ ), and correlation between these agonist responses was not significant $\left(R^{2}=0.17, p=0.083\right.$, data not shown). Last, normalized $I_{C a}$ inhibition CRCs for SCFAs or BHB were determined in sympathetic MPG neurons (Fig. $8 D$ ). Compared with heterologously expressed $\mathrm{rFFA} 3$ potencies $\left(\mathrm{EC}_{50}=12 \pm 1.1\right.$ and $477 \pm$ $1.1 \mu \mathrm{M}$ by $\mathrm{C} 3$ and $\mathrm{C} 2$, respectively), CRCs generated from natively expressed receptors in sympathetic MPG neurons were right-shifted $\left(\mathrm{EC}_{50}=276 \pm 1.2 \mu \mathrm{M}\right.$ and $5.2 \pm 1.3 \mathrm{~mm}$ for C3 and C2, respectively). Together, these results suggest that endogenously produced $\mathrm{BHB}$, under conditions, such as starvation and diabetes, could contribute to regulation of SNS activity through FFA3 in sympathetic ganglia.

\section{Discussion}

SCFAs are considered a minor nutrient source produced from enteric bacteria. However, the recently deorphanized GPCRs, FFA3 and FFA2, for which SCFAs are proposed ligands, provide an additional function for these molecules as initiating elements in signaling cascades. A key to understanding the physiological roles of these receptors lies with determining their location, endogenous ligands, signaling pathways, and effectors. In this study, we examined these questions in regard to function of FFA3 in the rat SNS.

\section{Abundant and variable expression of FFA3 in sympathetic ganglia}

Kimura et al. (2011) have shown that FFA3 is highly expressed in the SNS of mice and humans. This finding was unexpected 
A i. MPG neurons (SN)

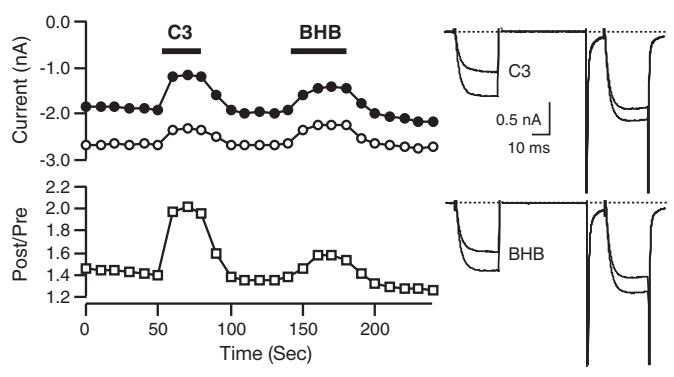

B

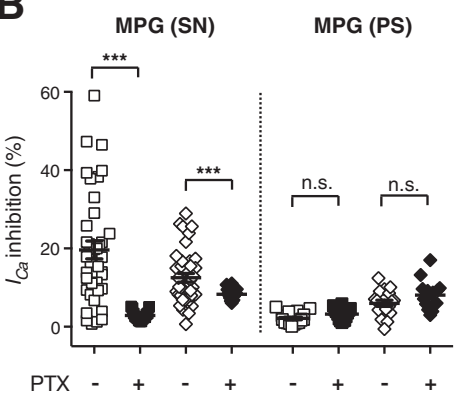

C

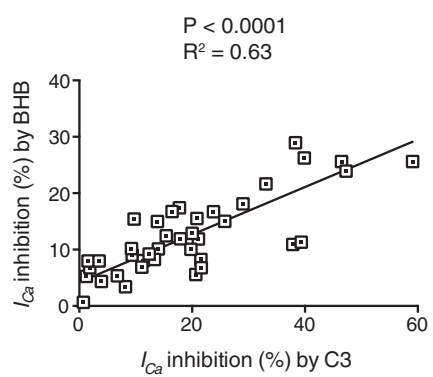

ii. MPG neurons (PS)

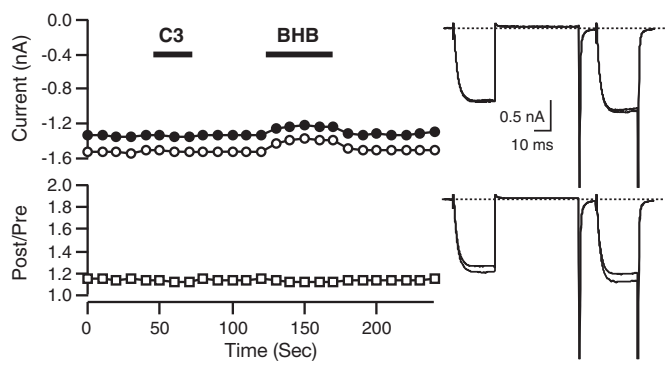

D $\begin{array}{ll}\text {-O- rFFA3 Inj. - C2 } & \text { O MPG (SN)-C2 } \\ -\square-\text { rFFA3 Inj. - C3 } & \text { MPG (SN)-C3 }\end{array}$

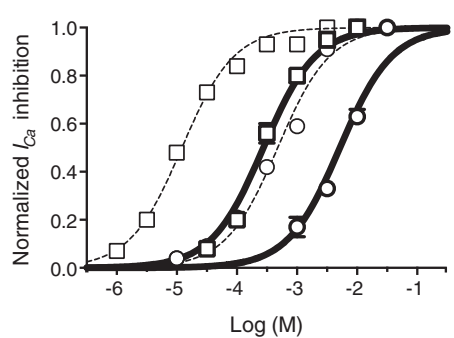

Figure 8. BHB induced $I_{C a}$ modulation via natively expressed FFA3 in sympathetic MPG neurons. $A$, Time courses of $I_{C a}$ and superimposed current traces evoked with the double-pulse voltage protocol from enzymatically dissociated sympathetic (SN, $\boldsymbol{A i}$ ) and parasympathetic (PS, Aii) MPG neurons. C3 (1 mM) was applied before BHB test to determine functional expression of native FFA3 in MPG neurons. After removal of $\mathrm{C} 3, \mathrm{BHB}(10 \mathrm{~mm})$ was applied to the same neurons. The horizontal bars represent the duration of $\mathrm{C} 3$ and $\mathrm{BHB}$ application. Superimposed current traces were obtained from the time point showing maximal $I_{C a}$ inhibition during drug application. $B$, Changes in $I_{C a}$ amplitude produced by $C 3$ (1 mM, squares) and BHB (10 mM, diamonds) from each tested sympathetic (SN) and parasympathetic (PS) MPG neuron are represented as individual points in the dot plot graph. Mean \pm SEM drug responses are represented as horizontal solid lines on the graph. Filled squares and diamonds on graph represent PTX ( $500 \mathrm{ng} / \mathrm{ml}$ ) pretreated groups. ${ }^{* * *} p<0.001$. n.s., No significant difference between groups ( $p>0.05$; unpaired $t$ test with Welch's correction). C, Peak of $I_{C a}$ inhibition $(\%)$ by BHB ( $y$-axis) versus C3 ( $x$-axis) was plotted and the correlation between the groups determined $\left(p<0.0001, R^{2}=0.63\right.$ ). The solid line represents the best linear fit as determined from Deming (orthogonal distance) regression. The slope was $0.42 \pm 0.05$ (slope $\pm 95 \%$ (I). D, Concentration-response curves for normalized $I_{C a}$ inhibition by C2 (filled circles) or C3 (filled squared) on natively expressed FFA3 in sympathetic MPG neurons (solid lines). For comparison, concentration-response curves for C2 (open circles) and C3 (open squares) on heterologously expressed rFFA3 in SCG neurons (from Figs. 2 and 5) are also normalized and represented on the same graph (dashed lines).

as previous work identified FFA3 expression in non-neuronal elements, such as enteroendocrine cells, monocytes, and WAT (Brown et al., 2003; Le Poul et al., 2003; Nilsson et al., 2003; Xiong et al., 2004). We extended this finding by showing that FFA3 expression and function within the rat SNS are unevenly distributed. The highest transcript levels and $I_{C a}$ modulation were detected in the prevertebral (CSMG, MPG) versus the paravertebral (SCG, SG) ganglia. This distribution provides some clues to physiological function. For example, prevertebral sympathetic neurons innervate a variety of visceral structures, including the resistance vasculature supplying the intestines. Moreover, $I_{C a}$ modulation was highly variable in neurons isolated from single ganglia suggesting that the innervation target may dictate FFA3 expression level. However, this remains speculative until methods for definitely tracing FFA3expressing neurons to target organs are developed. Transcript levels of FFA2, a paralog of FFA3, were particularly high in CSMG and, notably, higher than levels in WAT.

\section{Coupling of FFA3 to N-type $\mathrm{Ca}^{2+}$ channels in sympathetic neurons}

Direct effects of FFA3 activation on voltage-gated ion channel function have not been previously explored. Heterologous expression of FFAs in SCG neurons allowed us to characterize a molecularly defined FFA response in a native neuronal environment. Expression of FFA3 followed by $\mathrm{C} 2$ or C3 application produced $I_{C a}$ inhibition typical of $\mathrm{G} \alpha_{\mathrm{i} / \mathrm{o}}$-coupled GPCRs, which was rapid in both onset and washout, voltage-dependent, and greatly reduced by PTX pretreatment (Ikeda, 1991, 1996). FFA2 expression produced similar results that differed in two important aspects: (1) $\mathrm{C} 2$ and $\mathrm{C} 3$ potencies were similar for FFA2 as opposed to C3 $>\mathrm{C} 2$ potency for FFA3 (Fig. 2B); and (2) the majority of $\mathrm{C} 3$ response was insensitive to PTX. Both observations corroborate previous studies (Brown et al., 2003; Le Poul et al., 2003) and were helpful for interpreting C3-mediated $I_{C a}$ modulation via natively expressed receptors in CSMG and MPG neurons.

At native expression level, robust $I_{C a}$ modulation was observed in a subset of CSMG and sympathetic MPG neurons after C3 application. The modulation was rapid, reversible, voltagedependent, and completely abolished after overnight PTX treatment. Application of equimolar C2 (1 mM) did not produce overt modulation. Based on the minuscule $\mathrm{C} 2$ response and the abrogation of response by PTX treatment, we propose that FFA3 is the dominant participant in the $I_{C a}$ modulation by $\mathrm{C} 3$ despite the presence of FFA2 transcript in CSMG neurons. Very recently, Pluznick et al. (2013) reported that Olfr78, an olfactory family GPCR, was activated by C2 and C3 and found in sympathetic neurons (Weber et al., 2002). Olfr78 couples to PTX-insensitive G-proteins $\left(\mathrm{G}_{\mathrm{s}}\right.$ or $\left.\mathrm{G}_{\mathrm{olf}}\right)$ and thus unlikely to participate in the $I_{C a}$ modulation seen here. These interpretations are predicated on the heterologous properties of FFA2 and Olfr78 recapitulating native responses.

\section{BHB is an agonist of FFA3}

Unexpectedly, we found that BHB is an FFA3 agonist rather than antagonist as previously reported (Kimura et al., 2011). In FFA3 
heterologous expression studies, BHB application modulated $I_{\mathrm{Ca}}$ in neurons, activated GIRK channels in HEK293 cells, and inhibited forskolin-induced cAMP increases as determined by a BRET-based cAMP sensor. The results provide independent and convergent lines of evidence that BHB is an agonist at FFA3 coupled to effectors via $\mathrm{G} \alpha_{\mathrm{i} / \mathrm{o}}$, the channel effects being mediated by $\mathrm{G} \beta \gamma$ and the cAMP effects via $\mathrm{G} \alpha_{\mathrm{i}}$-GTP acting on adenylyl cyclase. In a native setting (MPG neurons), BHB and C3 modulation of $I_{\mathrm{Ca}}$ was correlated, suggesting that the same receptor was involved in both responses. We conclude that $\mathrm{BHB}$ serves as a potential endogenous agonist to modulate SNS function, a finding with important implications for the physiological role of FFA3. Kimura et al. (2011) provided in vivo, cellular, and biochemical evidence that BHB serves as an antagonist at FFA3, a result diametrically opposed to our findings. We initially performed experiments to examine whether BHB antagonized C3mediated $I_{C a}$ modulation, but our result revealed agonist activity. It is possible that $\mathrm{BHB}$ acts as a partial agonist and thus, depending on context (e.g., drug concentrations, receptor reserve, G-proteins), produces a wide spectrum of effects. Because of the low potency of $\mathrm{BHB}$, complete CRCs were problematic resulting from receptor-independent effects occurring at concentrations $>10 \mathrm{~mm}$. Within this constraint, the maximal efficacy of BHB was similar to $\mathrm{C} 2$ and $\mathrm{C} 3$ in a heterologous system (Fig. 5D). Currently, it is unclear why our results and those of Kimura et al. (2011) conflict, although differences in experimental conditions (e.g., rats vs mice, age of animals) are a likely possibility.

\section{Physiological consequences of FFA3 in the SNS}

There is a long history of correlation between somal $I_{C a}$ inhibition and decreases in catecholamine release from sympathetic nerve terminals (Hirning et al., 1988; Koh and Hille, 1997). We would thus argue that activation of FFA3 should suppress catecholamine release and thus sympathetic function. The tacit assumptions underlying this interpretation are that similar receptors and modulatory pathways are present on the nerve terminal.

At present, $\mathrm{C} 2, \mathrm{C} 3$, and $\mathrm{BHB}$ are candidates as endogenous agonists for FFA3 in sympathetic neurons. $\mathrm{C} 3$ is the most potent agonist, and levels clearly reach significant levels (e.g., 10-100 $\mathrm{mM}$ ) in the gut lumen after bacterial fermentation of dietary fiber. Hence, FFA3 receptors on enteroendocrine cells are exposed to relevant C3 concentrations. The situation is less clear for sympathetic neurons as human plasma levels of $\mathrm{C} 3$ are reported in the 5-90 $\mu \mathrm{M}$ range (Layden et al., 2013) depending on the vascular site. C2 also reaches high levels in the gut lumen and plasma levels of 100-300 $\mu \mathrm{M}$, likely subthreshold given our data (Fig. 8D). However, C2 plasma levels are elevated into the millimolar range after ethanol ingestion and during intravenous therapy with acetate-containing solutions (e.g., Ringer's acetate). Under these circumstances, C2 suppression of the SNS may be of clinical importance (Desch et al., 1978; Maxwell et al., 2010).

BHB may serve as the predominant physiologically relevant endogenous agonist for FFA3 in sympathetic neurons. Although BHB plasma levels in humans are normally $\sim 50-100 \mu \mathrm{M}$, the concentration rises into the $1-2 \mathrm{~mm}$ range after $2-3 \mathrm{~d}$ of fasting and higher $(6-8 \mathrm{~mm})$ with starvation. During diabetic ketoacidosis (Fulop et al., 1999) or in patients on a ketogenic diet for seizure control (Gilbert et al., 2000), serum BHB levels often exceed $10 \mathrm{~mm}$. Thus, although $\mathrm{BHB}$ is the least potent of the agonists, under defined conditions it may impact the SNS. In this regard, fasting/starvation in humans and mice, conditions known to raise plasma BHB levels, suppress the SNS (Young and
Landsberg, 1977; Landsberg, 2006). Thus, one could speculate that increases in plasma BHB activate FFA3 on sympathetic nerve terminals, inhibit $\mathrm{Ca}^{2+}$ channels, and decrease evoked norepinephrine release resulting in functional impairment of the SNS.

A problem with this hypothesis is the current controversy over the impact of FFA3 on in vivo phenotypes that relate to SNS function. For example, C3 administration results in increased firing rate of mouse sympathetic neurons, increases in norepinephrine release, and increases in heart rate (Kimura et al., 2011). Moreover, these effects appear to occur via FFA3 as they are reduced or eliminated in the $\mathrm{KO}$ mouse. $\mathrm{BHB}$ is proposed to antagonize these effects and thus produce suppression of the SNS. However, Pluznick et al. (2013) showed that propionate infusion depressed mean arterial pressure in mice, an effect that is reversed in the FFA3 $\mathrm{KO}$ animal. $\mathrm{C} 3$ effects on Olfr78 resulting in renin release from juxtaglomerular cells appear to underlie the hypertensive effect. Olfr78 is also putatively expressed in SNS neurons (Weber et al., 2002). Given the complexity of autonomic effects on cardiovascular function, potential compensatory effects of genetically ablating a particular GPCR, the increasing number of proteins that respond to SCFAs, and the influence of gut microbiota on FFA3 function, the contribution of FFA3 to SNS function requires further investigation.

In conclusion, we have shown that FFA3 is expressed differentially within the rat SNS, inhibits $\mathrm{N}$-type $\mathrm{Ca}^{2+}$ channels via PTX-sensitive G-proteins, and that propionate and BHB act as agonist on natively expressed receptors in prevertebral sympathetic neurons. As plasma BHB levels increase greatly during fasting, diabetic ketoacidosis, and ketogenic diets, we speculate that FFA3 may play important roles in the SNS during such conditions. However, the physiological consequences of BHB actions acting on FFA3 to modulate sympathetic neuron $\mathrm{Ca}^{2+}$ channels remain to be determined.

\section{References}

Brown AJ, Goldsworthy SM, Barnes AA, Eilert MM, Tcheang L, Daniels D, Muir AI, Wigglesworth MJ, Kinghorn I, Fraser NJ, Pike NB, Strum JC, Steplewski KM, Murdock PR, Holder JC, Marshall FH, Szekeres PG, Wilson S, Ignar DM, Foord SM, et al. (2003) The Orphan G proteincoupled receptors GPR41 and GPR43 are activated by propionate and other short chain carboxylic acids. J Biol Chem 278:11312-11319. CrossRef Medline

Brown AJ, Jupe S, Briscoe CP (2005) A family of fatty acid binding receptors. DNA Cell Biol 24:54-61. CrossRef Medline

Desch G, Oules R, Mion C, Descomps B, De Paulet AC (1978) Plasma acetate levels during hemodialysis. Clin Chim Acta 85:231-241. CrossRef Medline

Elmslie KS, Zhou W, Jones SW (1990) LHRH and GTP- $\gamma$-S modify calcium current activation in bullfrog sympathetic neurons. Neuron 5:75-80. CrossRef Medline

Fulop M, Murthy V, Michilli A, Nalamati J, Qian Q, Saitowitz A (1999) Serum $\beta$-hydroxybutyrate measurement in patients with uncontrolled diabetes mellitus. Arch Intern Med 159:381-384. CrossRef Medline

Gilbert DL, Pyzik PL, Freeman JM (2000) The ketogenic diet: seizure control correlates better with serum $\beta$-hydroxybutyrate than with urine ketones. J Child Neurol 15:787-790. CrossRef Medline

Hamill OP, Marty A, Neher E, Sakmann B, Sigworth FJ (1981) Improved patch-clamp techniques for high-resolution current recording from cells and cell-free membrane patches. Pflugers Arch 391:85-100. CrossRef Medline

Hirning LD, Fox AP, McCleskey EW, Olivera BM, Thayer SA, Miller RJ, Tsien RW (1988) Dominant role of $\mathrm{N}$-type $\mathrm{Ca}^{2+}$ channels in evoked release of norepinephrine from sympathetic neurons. Science 239:57-61. CrossRef Medline

Hong YH, Nishimura Y, Hishikawa D, Tsuzuki H, Miyahara H, Gotoh C, Choi KC, Feng DD, Chen C, Lee HG, Katoh K, Roh SG, Sasaki S (2005) 
Acetate and propionate short chain fatty acids stimulate adipogenesis via GPCR43. Endocrinology 146:5092-5099. CrossRef Medline

Ikeda SR (1991) Double-pulse calcium channel current facilitation in adult rat sympathetic neurones. J Physiol 439:181-214. Medline

Ikeda SR (1996) Voltage-dependent modulation of N-type calcium channels by G-protein $\beta \gamma$ subunits. Nature 380:255-258. CrossRef Medline

Ikeda SR (2004) Expression of G-protein signaling components in adult mammalian neurons by microinjection. Methods Mol Biol 259:167-181. CrossRef Medline

Ikeda SR, Dunlap K (1999) Voltage-dependent modulation of N-type calcium channels: role of G protein subunits. Adv Second Messenger Phosphoprotein Res 33:131-151. CrossRef Medline

Ikeda SR, Jeong SW (2004) Use of RGS-insensitive G $\alpha$ subunits to study endogenous RGS protein action on G-protein modulation of N-type calcium channels in sympathetic neurons. Methods Enzymol 389:170-189. CrossRef Medline

Ikeda SR, Schofield GG (1989) Somatostatin blocks a calcium current in rat sympathetic ganglion neurones. J Physiol 409:221-240. Medline

Jiang LI, Collins J, Davis R, Lin KM, DeCamp D, Roach T, Hsueh R, Rebres RA, Ross EM, Taussig R, Fraser I, Sternweis PC (2007) Use of a cAMP BRET sensor to characterize a novel regulation of cAMP by the sphingosine 1-phosphate/G13 pathway. J Biol Chem 282:10576-10584. CrossRef Medline

Karaki S, Tazoe H, Hayashi H, Kashiwabara H, Tooyama K, Suzuki Y, Kuwahara A (2008) Expression of the short-chain fatty acid receptor, GPR43, in the human colon. J Mol Histol 39:135-142. CrossRef Medline

Keast JR (1995) Visualization and immunohistochemical characterization of sympathetic and parasympathetic neurons in the male rat major pelvic ganglion. Neuroscience 66:655-662. CrossRef Medline

Kebede MA, Alquier T, Latour MG, Poitout V (2009) Lipid receptors and islet function: therapeutic implications? Diabetes Obes Metab 11 [Suppl 4]:10-20.

Kimura I, Inoue D, Maeda T, Hara T, Ichimura A, Miyauchi S, Kobayashi M, Hirasawa A, Tsujimoto G (2011) Short-chain fatty acids and ketones directly regulate sympathetic nervous system via $G$ protein-coupled receptor 41 (GPR41). Proc Natl Acad Sci U S A 108:8030-8035. CrossRef Medline

Koh DS, Hille B (1997) Modulation by neurotransmitters of catecholamine secretion from sympathetic ganglion neurons detected by amperometry. Proc Natl Acad Sci U S A 94:1506-1511. CrossRef Medline

Landsberg L (2006) Feast or famine: the sympathetic nervous system response to nutrient intake. Cell Mol Neurobiol 26:497-508. CrossRef Medline

Layden BT, Angueira AR, Brodsky M, Durai V, Lowe WL Jr (2013) Short chain fatty acids and their receptors: new metabolic targets. Transl Res 161:131-140. CrossRef Medline

Lee JH, Kim EG, Park BG, Kim KH, Cha SK, Kong ID, Lee JW, Jeong SW (2002) Identification of T-type $\alpha 1 \mathrm{H} \mathrm{Ca}^{2+}$ channels $(\mathrm{Ca}(\mathrm{v}) 3.2)$ in major pelvic ganglion neurons. J Neurophysiol 87:2844-2850. Medline

Le Poul E, Loison C, Struyf S, Springael JY, Lannoy V, Decobecq ME, Brezillon S, Dupriez V, Vassart G, Van Damme J, Parmentier M, Detheux M (2003) Functional characterization of human receptors for short chain fatty acids and their role in polymorphonuclear cell activation. J Biol Chem 278:25481-25489. CrossRef Medline

Lu VB, Williams DJ, Won YJ, Ikeda SR (2009) Intranuclear microinjection of DNA into dissociated adult mammalian neurons. J Vis Exp 10:e1614. CrossRef Medline

Maxwell CR, Spangenberg RJ, Hoek JB, Silberstein SD, Oshinsky ML (2010) Acetate causes alcohol hangover headache in rats. PLoS One 5:e15963. CrossRef Medline

Nilsson NE, Kotarsky K, Owman C, Olde B (2003) Identification of a free fatty acid receptor, FFA2R, expressed on leukocytes and activated by short-chain fatty acids. Biochem Biophys Res Commun 303:1047-1052. CrossRef Medline
Pluznick JL, Protzko RJ, Gevorgyan H, Peterlin Z, Sipos A, Han J, Brunet I, Wan LX, Rey F, Wang T, Firestein SJ, Yanagisawa M, Gordon JI, Eichmann A, Peti-Peterdi J, Caplan MJ (2013) Olfactory receptor responding to gut microbiota-derived signals plays a role in renin secretion and blood pressure regulation. Proc Natl Acad Sci U S A 110:4410-4415. CrossRef Medline

Samuel BS, Shaito A, Motoike T, Rey FE, Backhed F, Manchester JK, Hammer RE, Williams SC, Crowley J, Yanagisawa M, Gordon JI (2008) Effects of the gut microbiota on host adiposity are modulated by the short-chain fatty-acid binding G protein-coupled receptor, Gpr41. Proc Natl Acad Sci U S A 105:16767-16772. CrossRef Medline

Schmittgen TD, Livak KJ (2008) Analyzing real-time PCR data by the comparative $C(T)$ method. Nat Protoc 3:1101-1108. CrossRef Medline

Schofield GG, Puhl HL 3rd, Ikeda SR (2008) Properties of wild-type and fluorescent protein-tagged mouse tetrodotoxin-resistant sodium channel $\left(\mathrm{Na}_{\mathrm{V}} 1.8\right)$ heterologously expressed in rat sympathetic neurons. J Neurophysiol 99:1917-1927. CrossRef Medline

Sellin JH (1999) SCFAs: the enigma of weak electrolyte transport in the colon. News Physiol Sci 14:58-64. Medline

Taggart AK, Kero J, Gan X, Cai TQ, Cheng K, Ippolito M, Ren N, Kaplan R, Wu K, Wu TJ, Jin L, Liaw C, Chen R, Richman J, Connolly D, Offermanns S, Wright SD, Waters MG (2005) (D)-beta-Hydroxybutyrate inhibits adipocyte lipolysis via the nicotinic acid receptor PUMA-G. J Biol Chem 280:26649-26652. CrossRef Medline

Tazoe H, Otomo Y, Karaki S, Kato I, Fukami Y, Terasaki M, Kuwahara A (2009) Expression of short-chain fatty acid receptor GPR41 in the human colon. Biomed Res 30:149-156. CrossRef Medline

Topping DL, Clifton PM (2001) Short-chain fatty acids and human colonic function: roles of resistant starch and nonstarch polysaccharides. Physiol Rev 81:1031-1064. Medline

Tunaru S, Kero J, Schaub A, Wufka C, Blaukat A, Pfeffer K, Offermanns S (2003) PUMA-G and HM74 are receptors for nicotinic acid and mediate its anti-lipolytic effect. Nat Med 9:352-355. CrossRef Medline

Vivaudou M, Chan KW, Sui JL, Jan LY, Reuveny E, Logothetis DE (1997) Probing the G-protein regulation of GIRK1 and GIRK4, the two subunits of the KACh channel, using functional homomeric mutants. J Biol Chem 272:31553-31560. CrossRef Medline

Weber M, Pehl U, Breer H, Strotmann J (2002) Olfactory receptor expressed in ganglia of the autonomic nervous system. J Neurosci Res 68:176-184. CrossRef Medline

Wise A, Foord SM, Fraser NJ, Barnes AA, Elshourbagy N, Eilert M, Ignar DM, Murdock PR, Steplewski K, Green A, Brown AJ, Dowell SJ, Szekeres PG, Hassall DG, Marshall FH, Wilson S, Pike NB (2003) Molecular identification of high and low affinity receptors for nicotinic acid. J Biol Chem 278:9869-9874. CrossRef Medline

Xiong Y, Miyamoto N, Shibata K, Valasek MA, Motoike T, Kedzierski RM, Yanagisawa M (2004) Short-chain fatty acids stimulate leptin production in adipocytes through the $\mathrm{G}$ protein-coupled receptor GPR41. Proc Natl Acad Sci U S A 101:1045-1050. CrossRef Medline

Young JB, Landsberg L (1977) Suppression of sympathetic nervous system during fasting. Science 196:1473-1475. CrossRef Medline

Zaibi MS, Stocker CJ, O'Dowd J, Davies A, Bellahcene M, Cawthorne MA, Brown AJ, Smith DM, Arch JR (2010) Roles of GPR41 and GPR43 in leptin secretory responses of murine adipocytes to short chain fatty acids. FEBS Lett 584:2381-2386. CrossRef Medline

Zhu Y, Ikeda SR (1993a) Adenosine modulates voltage-gated $\mathrm{Ca}^{2+}$ channels in adult rat sympathetic neurons. J Neurophysiol 70:610-620. Medline

Zhu Y, Ikeda SR (1993b) 2,3-Butanedione monoxime blockade of $\mathrm{Ca}^{2+}$ currents in adult rat sympathetic neurons does not involve "chemical phosphatase" activity. Neurosci Lett 155:24-28. CrossRef Medline

Zhu Y, Zboran EL, Ikeda SR (1995) Phenotype-specific expression of T-type calcium channels in neurons of the major pelvic ganglion of the adult male rat. J Physiol 489:363-375. Medline 